\title{
Strengthening of reinforced concrete shear walls with openings using carbon fiber-reinforced polymers
}

\author{
Mohamed Husain ${ }^{1} \cdot$ Ahmed S. Eisa $^{1} \cdot$ Mohamed M. Hegazy ${ }^{1}$
}

Received: 13 November 2018 / Accepted: 31 January 2019 / Published online: 13 February 2019

(c) The Author(s) 2019

\begin{abstract}
Reinforced concrete shear walls are one of the most widely used lateral load structural resisting elements in high rise buildings. Introducing openings in existing shear walls may be due to remodeling or municipality considerations, such as placement of staircases, windows, doors and elevators. Making openings in existing shear wall decrease the overall structural capacity and integrity of the wall, in addition to stress concentrations around the openings. This necessitates the strengthening of the opening rim with FRP wraps. This paper focuses on developing a 3D high-reliability dynamic nonlinear finite element model on ABAQUS theory manual and users' manual, version 6.10 (2010) to simulate the behavior of shear walls with openings strengthened with FRP wraps to investigate their seismic response under the monotonic loads. The proposed FE model has been validated using previous experimental data in literature. The FE results indicated that the proposed configuration of CFRP laminates substantially increases the lateral load strength and deformation capacity of the shear wall with openings and also improves the ductility and energy dissipation of the shear wall.
\end{abstract}

Keywords Shear wall $\cdot$ Openings $\cdot 3$ D numerical analysis $\cdot$ Strengthening $\cdot$ CFRP $\cdot$ Ductility

\section{List of symbols}

$f_{\mathrm{c}}^{\prime} \quad$ Characteristic compressive strength of concrete (MPa)

$E_{\mathrm{c}} \quad$ Elastic modulus (MPa)

$E_{0} \quad$ Initial elastic modulus $(\mathrm{MPa})$

$\sigma_{\mathrm{c}} \quad$ Compressive stress of concrete (MPa)

$\varepsilon_{\mathrm{c}} \quad$ Concrete strain

$\varepsilon_{\mathrm{cu}} \quad$ Ultimate strain of concrete

$\varepsilon_{0} \quad$ Strain at the peak stress

$f_{\text {ctm }} \quad$ Average tensile strength of concrete (MPa)

$\mathrm{f}_{\mathrm{cm}} \quad$ Average compressive strength of concrete (MPa)

$F_{\text {y }} \quad$ Yield strength of steel (MPa)

$F_{\mathrm{u}} \quad$ Ultimate strength of steel (MPa)

$f_{\text {fu }} \quad$ Ultimate tensile strength of FRP (MPa)

$v \quad$ Poisson's ratio

Ahmed S. Eisa

ahmedeisa@zu.edu.eg

Mohamed Husain

Mo_husain2000@yahoo.com

Mohamed M. Hegazy

engineermony2012@gmail.com

1 Department of Structural Engineering, Zagazig University, Zagazig 44519, Egypt
$R, R_{\mathrm{E},} R_{\sigma} \quad$ Parameters depend on concrete properties

$K_{\mathrm{i}} \quad$ Secant stiffness $(\mathrm{kN} / \mathrm{mm})$

$F_{\mathrm{i}} \quad$ Peak load $(\mathrm{kN})$

$X_{\mathrm{i}} \quad$ Displacement (mm)

$\varepsilon_{\mathrm{t}} \quad$ Total strain

$\varepsilon_{t}^{\mathrm{cr}} \quad$ Cracking strain of concrete

$\varepsilon_{t}^{\mathrm{pl}} \quad$ Plastic strain of concrete

$d_{\mathrm{t}} \quad$ Tensile damage parameter

$d_{\text {c }} \quad$ Compression damage parameter

$\sigma_{\mathrm{t}} \quad$ Tensile stress of concrete $(\mathrm{MPa})$

$\varepsilon_{t}^{\mathrm{el}} \quad$ Elastic strain

$\mathrm{k} \quad$ Ratio of the second stress invariant on the tensile meridian to that of compressive meridian

$f_{\mathrm{b} 0} / f_{\text {co }} \quad$ Ratio of initial equibiaxial yield stress to initial uniaxial compressive stress

$\varepsilon_{\mathrm{fu}} \quad$ Ultimate strain of FRP

$G \quad$ Shear modulus (MPa)

$t \quad$ FRP layer thickness (mm)

$P_{\mathrm{u}} \quad$ Ultimate load $(\mathrm{kN})$

$\Delta_{\mathrm{u}} \quad$ Ultimate displacement ( $\left.\mathrm{mm}\right)$

$\Delta_{\mathrm{y}} \quad$ Yield displacement (mm)

$n \quad$ Number of layers

$E_{\mathrm{b}} \quad$ Energy absorption capacity $(\mathrm{kN} \mathrm{mm})$

$\mu \quad$ Ductility index 


\section{Introduction}

Reinforced concrete shear walls represent a structurally efficient solution to stiffen a building structural system under lateral loads. The main function of a shear wall is to increase the rigidity and strength of the building for lateral resistance. Shear walls have very high in-plane stiffness and strength, which can be used to instantaneously resist large horizontal loads such as wind or seismic forces in addition to resisting gravity loads. RC shear walls must be carefully designed to provide not only adequate strength, but also sufficient ductility to avoid brittle shear failures. Several shear walls all over the world are suffering damages from earthquakes or due to poor design and detailing or have construction faults. As mentioned in Popescu et al. (2015), the description of shear wall openings could be defined as already existing openings, or existing openings that have been enlarged and newly created openings. The introduction of openings in walls due to the architecture and installation's needs will change the stress distribution within the wall, adversely influencing its strength. Investigations on the behavior of reinforced concrete members strengthened by externally bonded FRP have been mainly focused on either columns or beams, while there are limited experimental and analytical studies exploring the effectiveness of FRP retrofitting and strengthening the structural walls with or without openings.

Experimental investigations on the rehabilitation of shear walls by CFRP strips have been performed by many researchers. According to Lombard et al. (2000), the strengthening of shear walls using carbon fiber-reinforced polymers (CFRP) have been performed to increase its strength and ductility. The study presented shear walls that were strengthened by CFRP strips oriented in the vertical direction to the two faces of the walls. The results showed good improvement of flexural capacity and secant stiffness of the structural wall. Ghobarah and Khalil (2004) have retrofitted RC walls with FRP composites to improve the wall capacity to seismic loads and also to increase ductility. The rehabilitated walls were wrapped with bi-directional sheets in the wall region and uni-directional sheets on the boundary elements. The experimental results showed the improvement of the structural capacity of shear walls under lateral loading and the strip configurations has a major effect on the behavior of the strengthened walls and failure modes.

Antoniades et al. (2003) have retrofitted RC squat shear walls with FRP jackets in combination of FRP strips to increase the strength of heavily damaged walls during earthquake. The results indicated that the repaired wall showed improvement in the original strength with less initial stiffness and energy dissipation capacity. Altin et al. (2013) have constructed and tested five shear walls strengthened with CFRP strips with different configurations under reversed cyclic lateral loading. The experimental results indicated that the best performance has been obtained from the strengthening with lateral strips and showed the improvement of hysteretic behavior and displacement capacity as well.

Mosallam and Nasr (2016) have experimentally investigated the strengthening of reinforced concrete shear walls with openings using CFRP composite laminates under cyclic lateral loading. The experimental results indicated that the average peak loads of the CFRP-strengthened wall specimens with central window opening (R-WO) and eccentric door opening (R-DO) were 1.32, 1.25 times the average peak load of the unstrengthened walls with window opening (C-WO) and door opening (C-DO), respectively. On the other hand, the results showed that the CFRP-strengthened wall with central window opening (R-WO) had the highest toughness and ductility between all wall specimens and the CFRP strip configurations have a significant effect on the performance of the strengthened walls and failure modes. Mohammed et al. (2013) have constructed and tested oneway RC walls with cut out openings subjected to a uniformly distributed axial load with an eccentricity. They have applied two different CFRP patterns for strengthening these opening. The experimental results showed that applying the first and second patterns of CFRP strips around the corners of small openings (5\% of the wall area) increased the axial strength of the wall by $49.9 \%, 75.4 \%$, respectively. The results showed the improvement of the axial strength when applying CFRP inclined at $45^{\circ}$ to the small openings.

Behfarnia and Sayah (2012) have developed finite element method to predict the ultimate capacity of concrete shear walls with openings strengthened by FRP and verified with experimental data. The FE results showed the improvement of the ultimate load and displacement capacity of the shear wall. The size and location of openings have a major effect on the wall capacity. Behfarnia and Shirneshana (2017) have developed a nonlinear FE model to investigate the lateral behavior of the squat shear wall with opening strengthened by FRP strips with four different configurations. The FE results showed the improvement of the lateral load capacity and lateral displacement of the shear wall. Briefly, this paper mainly focused on investigating the structural behavior of the RC shear walls with openings strengthened by CFRP composite laminates under monotonic lateral loading using finite element (FE) analysis. The FE models of RC walls with openings were created using (ABAQUS/Explicit) version (6.14) software. Element types, geometric nonlinearity, material nonlinearity, constitutive models and interaction models for CFRP and concrete were proposed. Based on the verified FE model, parametric study was established to predict the performance of the RC shear walls with openings strengthened by CFRP laminates. The effect of CFRP laminates on strengthening of $\mathrm{RC}$ beams with openings has 
been studied by Mahmoud (2012) and has also developed a numerical model using (ANSYS) finite element software.

The studied walls have cross section of $100 \times 250 \times 2500 \mathrm{~mm}$. For strengthened walls with openings, they have dimensions of $150 \times 300 \mathrm{~mm}$ where two different CFRP configurations for strengthening have been applied. The mechanical properties for the used CFRP laminates are indicated in Table 1 . The FE results showed the improvement of flexural behavior, ultimate capacity and ultimate deflection of the strengthened beams. CFRP retrofitting schemes enhanced the crack patterns at the opening zone.

\section{Experimental testing}

Three shear wall specimens SW1, SW4 and SW8 were tested by Mosoarca (2013) and simulated by numerical concrete damage plasticity (CDP) constitutive model using ABAQUS. In general, the experimental procedure consisted of five types of walls: three had staggered openings (SW23, SW45 and SW67), one with regular openings (SW8) and one without openings (SW1). These specimens are in $1 / 4$ scale and were tested to evaluate the failure modes of the structural walls. Test setup, reinforcement details of the walls, and the walls dimensions are given in Fig. 1. All walls were analyzed first using a 2D SAP 2000 software where horizontal loads were simulated as equivalent static forces. The 2D analysis has been used to determine the wall dimensions and the reinforcement needed based on the ACI 318-14.

These specimens have identical geometric dimensions and reinforcement configurations. The wall specimens were $2600 \mathrm{~mm}$ in height and had a rectangular cross section of $1250 \times 80 \mathrm{~mm}$. The flexure and shear reinforcements consisted of 6-mm-diameter rebar located on both sides of the wall. The height-width ratios of these specimens are all around 2. Specimens consisted of three structural parts, namely, the $U$ steel plate through which the lateral loads were transferred into the wall, the wall panel, and the footing that was used for the

Table 1 Mechanical properties of CFRP laminates used in this analysis (Mahmoud 2012)

\begin{tabular}{lll}
\hline Nominal thickness (mm) & $t$ & 0.13 \\
Elastic modulus (MPa) & $E_{1}$ & 230,000 \\
& $E_{2}$ & 17,900 \\
Tensile strength (MPa) & $f_{\mathrm{fu}}$ & 3500 \\
Shear modulus (MPa) & $G_{12}$ & 11,790 \\
& $G_{13}$ & 11,790 \\
Poisson's ratio (V) & $G_{23}$ & 6880 \\
& $v_{12}$ & 0.22 \\
Ultimate strain (\%) & $v_{13}$ & 0.22 \\
\hline
\end{tabular}

anchoring the specimen onto the solid floor as a fixation. The out-of-plane movements were restrained by lateral supports.

The average compressive strength of concrete used in this study was measured as $50 \mathrm{MPa}$. The mechanical properties of concrete and steel reinforcement are summarized in Table 2. The experimental program procedure included two-loading stages: a constant axial force $(50 \mathrm{kN})$ is firstly applied on the top surface of the wall, and then the horizontal lateral load is imposed on the top through displacement control protocol.

To avoid the local crushing of the concrete at the application point of the horizontal and vertical loads, a rigid steel plate (with $25 \mathrm{~mm}$ thickness) was set on the top surface of the wall models. Specimens SW4 and SW8 were the reference specimen tested without strengthening.

\section{Finite element modeling (FEM)}

\section{Concrete}

For concrete modeling, the concrete damaged plasticity (CDP) model available in the material library of ABAQUS (2010) is adopted to simulate the nonlinear behavior of concrete. This model assumes that the two main failure mechanisms of the concrete material may occur, tensile cracking and compressive crushing. The CDP model requires the material stress-strain relationship based on the input of stress versus inelastic strain. For compressive stress-strain relationship, the model proposed by Saenz (1964) was used. The relationship between the compressive stress, $\sigma_{\mathrm{c}}$, and the corresponding strain, $\varepsilon_{\mathrm{c}}$, is presented as follows:

$\sigma_{\mathrm{c}}=\left[\frac{E_{\mathrm{c}} \varepsilon_{\mathrm{c}}}{1+\left(R+R_{\mathrm{E}}-2\right)\left(\frac{\varepsilon_{\mathrm{c}}}{\varepsilon_{0}}\right)-(2 R-1)\left(\frac{\varepsilon_{\mathrm{c}}}{\varepsilon_{0}}\right)^{2}+R\left(\frac{\varepsilon_{\mathrm{c}}}{\varepsilon_{0}}\right)^{3}}\right]$,

where $\varepsilon_{0}=0.0025, R_{\mathrm{E}}=4, R_{\sigma}=4$ as adopted in $\mathrm{Hu}$ and Schnobrich (1989). $f_{c}^{\prime}$ is the compressive strength of concrete and $\mathrm{E}_{\mathrm{c}}$ is the elastic modulus which is calculated according to (ACI-318 2016).

$$
\begin{aligned}
& R=\frac{R_{\mathrm{E}}\left(R_{\sigma}-1\right)}{\left(R_{\mathrm{E}}-1\right)^{2}}-\frac{1}{R_{\mathrm{E}}}, \\
& R_{\mathrm{E}}=\frac{E_{\mathrm{c}}}{E_{0}}, \\
& \mathrm{E}_{0}=\frac{f_{\mathrm{c}}^{\prime}}{\varepsilon_{0}} \\
& \mathrm{E}_{c}=4700 \sqrt{f_{\mathrm{c}}^{\prime}}
\end{aligned}
$$


Fig. 1 Test setup and rebar details
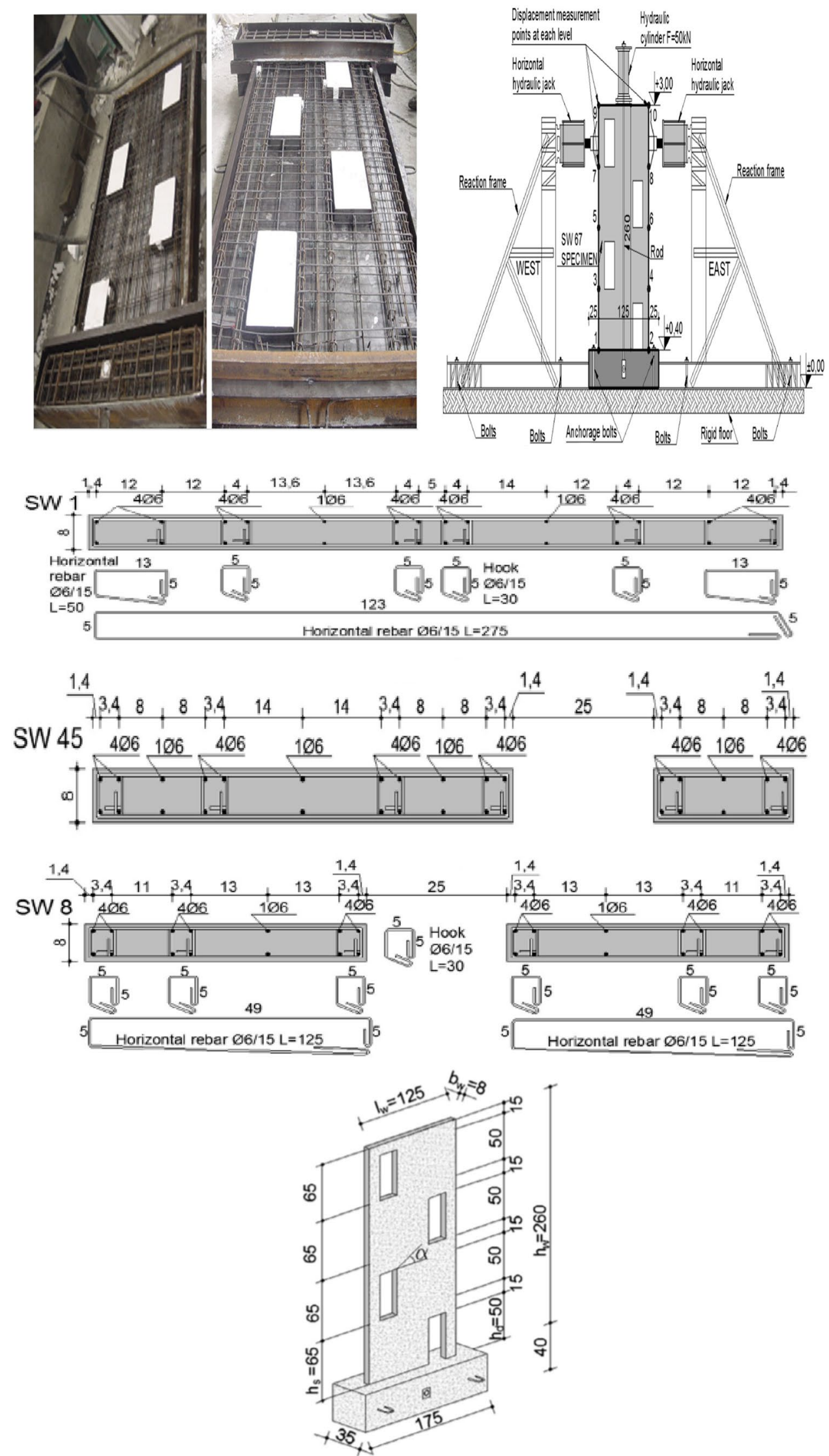
Table 2 Material properties of RC shear wall models

\begin{tabular}{lllll}
\hline Type & Diameter & Yield strength & Ultimate strength & Modulus of elasticity \\
\hline Rebars & $6 \mathrm{~mm}$ & $F_{\mathrm{y}}=386 \mathrm{MPa}$ & $F_{\mathrm{u}}=551 \mathrm{MPa}$ & $210,000 \mathrm{MPa}$ \\
\hline \multirow{2}{*}{ Concrete } & Average tensile strength $\left(f_{\mathrm{ctm}}\right)$ & Average compressive strength $\left(f_{\mathrm{cm}}\right)$ & Compressive strain & Modulus of elasticity \\
\hline
\end{tabular}

Table 3 The plasticity parameters used in this analysis

\begin{tabular}{lllll}
\hline Dilation angle & Eccentricity & $f_{\mathrm{bo}} / f_{\text {co }}$ & $k$ & Viscosity parameter \\
\hline 37 & 0.1 & 1.16 & 0.67 & 0.001 \\
\hline
\end{tabular}

For the CDP model, several parameters are required including the elastic modulus which is defined in Eq. (5), Poisson's ratio and the plasticity parameters. The plasticity parameters required by CDP model in ABAQUS which are summarized in Table 3 except the dilation angle value that was chosen by Kmiecik and Kaminski (2011). For concrete under uniaxial tension, tension stiffening behavior is assumed to simulate the post-cracking tensile behavior. Concrete is assumed to be linear elastic up to tensile cracking strength $\left(f_{\mathrm{ctm}}\right)$ and followed by strain softening. The postcracking behavior is defined in terms of stress versus cracking strain. The tension stiffening model proposed by Nayal and Rasheed (2006) was used. The nonlinear behavior of concrete to uniaxial tension and uniaxial compression is shown in Fig. 2.

\section{Definition of damage evolution}

In ABAQUS, the CDP model requires the definition of damage parameters, namely $d_{\mathrm{t}}$ and $d_{\mathrm{c}}$, which are developed to model the degradation of the concrete stiffness when subjected to monotonic loading. In this study, the evolution of the compressive and tensile damage parameters, $d_{\mathrm{c}}$ and $d_{\mathrm{t}}$,
Fig. 2 a, b The nonlinear behavior of concrete to uniaxial tension and uniaxial compression. c Modified tension stiffening model, $\mathbf{d}$ elastic perfectly plastic model for ABAQUS
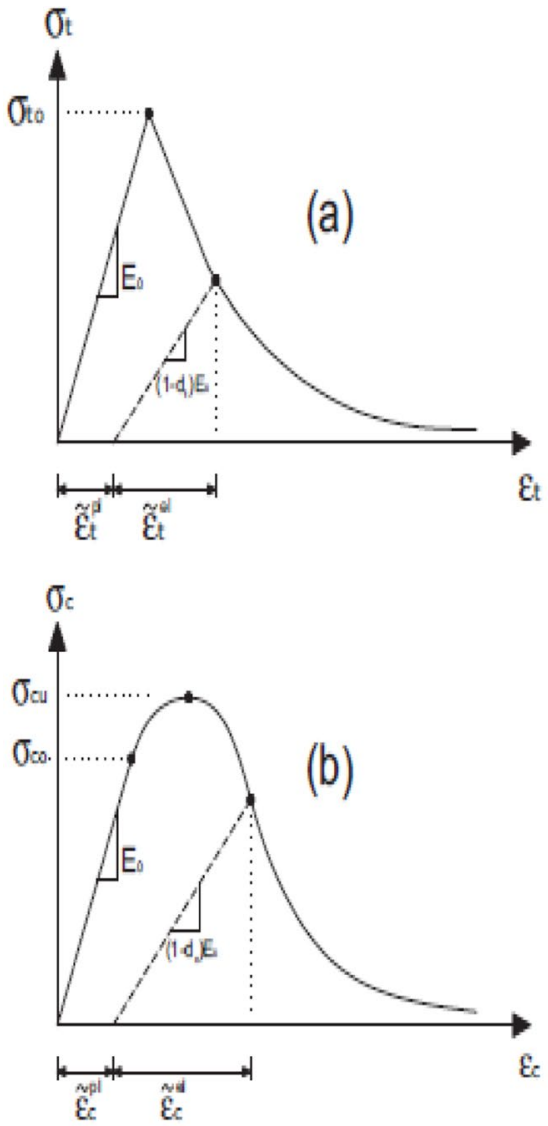

(a)
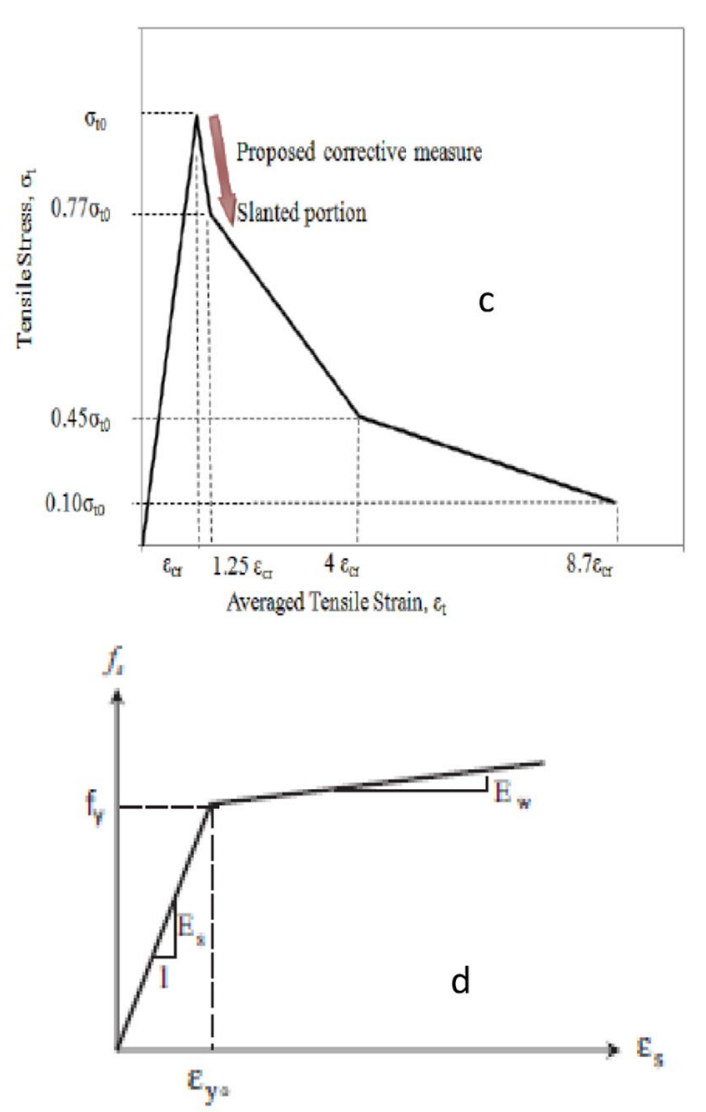

(b) 
respectively, which was defined by simplification in a linear damage parameter-strain relationship.

The maximum value of these damage variables, $d_{\mathrm{t}}$ and $d_{\mathrm{c}}$, is assumed to be 0.9 , which represents the total degradation of the concrete material Mosoarca (Mosoarca 2013). For CDP model, perfectly plastic behavior is defined in terms of inelastic strain and yield stress. If the concrete is undamaged after entering the softening range $\left(\varepsilon_{\mathrm{t}}>\sigma_{\mathrm{t}} / E_{\mathrm{c}}\right)$, the unloading path of the stress-strain curve has a slope equal to $E_{\mathrm{c}}$, and the corresponding elastic strain $\varepsilon_{\mathrm{t}, \mathrm{d}}^{\mathrm{el}}=\sigma_{\mathrm{t}} / E_{\mathrm{c}}$, where $\sigma_{\mathrm{t}}$ is the tensile stress in the concrete. If the concrete is damaged because of cracking, the slope of the unloading path is reduced to $\left(1-d_{\mathrm{t}}\right) E_{\mathrm{c}}$, and the corresponding elastic strain $\varepsilon_{\mathrm{t}}^{\mathrm{el}}=\sigma_{\mathrm{t}} /\left(1-d_{\mathrm{t}}\right) \mathrm{E}_{\mathrm{c}} \mathrm{l}$, where $d_{\mathrm{t}}$ is the tensile damage factor of cracked concrete. In ABAQUS, the cracking strain of cracked concrete is defined according to Eq. 6 that reported by Lubliner et al. (1989):

$\varepsilon_{\mathrm{t}}^{\mathrm{cr}}=\varepsilon_{\mathrm{t}}-\varepsilon_{\mathrm{t}}^{\mathrm{el}}$.

For damaged concrete, the equivalent plastic strain is defined as:

$\varepsilon_{\mathrm{t}}^{\mathrm{pl}}=\varepsilon_{\mathrm{t}}-\varepsilon_{\mathrm{t}, \mathrm{d}}^{\mathrm{el}}$.

Concrete compression damage parameter that is used in the proposed model is given by (Birtel and Mark 2006):

$d_{\mathrm{c}}=1-\frac{\sigma_{\mathrm{c}} E_{\mathrm{c}}^{-1}}{\varepsilon_{\mathrm{c}}^{\mathrm{pl}}\left(\frac{1}{b_{\mathrm{c}}}-1\right)+f_{\mathrm{c}} E_{\mathrm{c}}^{-1}}$,

where $d_{\mathrm{c}}$ is the concrete compression damage parameter, $f_{\mathrm{c}}$ is the compressive stress, $E_{\mathrm{c}}$ is the modulus of elasticity of concrete, $\varepsilon_{\mathrm{c}}^{\mathrm{pl}}$ is the Plastic strain corresponding to compressive strength, $b_{\mathrm{c}}$ is the Constant ranges $0<b_{\mathrm{c}}<1$.

Whereas concrete tension damage parameter is (Birtel and Mark 2006)

$d_{\mathrm{t}}=1-\frac{\sigma_{\mathrm{t}} E_{\mathrm{c}}^{-1}}{\varepsilon_{\mathrm{t}}^{\mathrm{pl}}\left(\frac{1}{b_{t}}-1\right)+f_{\mathrm{t}} E_{\mathrm{c}}^{-1}}$,

where $d_{\mathrm{t}}$ is the concrete tension damage parameter, $f_{\mathrm{t}}$ is the tensile stress, $E_{\mathrm{c}}$ is the modulus of elasticity of concrete, $\varepsilon_{\mathrm{t}}^{\mathrm{pl}}$ is the plastic strain corresponding to tensile strength, $b_{\mathrm{t}}$ is the constant ranges $0<b_{\mathrm{t}}<1$.

\section{Steel reinforcement}

In ABAQUS, longitudinal and transverse steel reinforcements are modeled with three-dimensional, two-node truss elements (T2D3) embedded in a concrete region. Elasticperfectly plastic behavior is assumed to model the steel reinforcement under both compression and tension. Linear elastic behavior is defined by elastic modulus and Poisson's ratio.

\section{CFRP composite}

CFRP material is usually considered as transversely linear elastic isotropic material until failure. Since the composite is unidirectional, it is clear that the behavior is essentially orthotropic. In ABAQUS, lamina behavior is used to define transversely isotropic material that requires five constitutive constants to define the stress-strain relationship. Hence, in the present study, an isotropic model was considered. Perfect bond is also assumed to define the interaction between Concrete and CFRP laminates. The elastic modulus in the fiber direction of the unidirectional CFRP material considered for the numerical simulation is $230 \mathrm{GPa}$. The orthotropic mechanical properties of the used laminates are taken according to the values that reported by Mahmoud (2012). CFRP is modeled using three-dimensional reduced integration shell element (S4R). The bond between CFRP and concrete was assumed as perfect to avoid its premature failure.

\section{Element types and meshing}

The software ABAQUS version 6.14 was adopted to simulate the nonlinear FE model of the specimens. The eightnode brick element with three translational degrees of freedom at each node (C3D8R) was used to model the concrete and steel plate. The four-node shell element with reduced integration (S4R) was used to model the CFRP laminates. The steel reinforcement was simulated by two-node truss elements with three translational degrees of freedom at each node (T3D2). To verify the mesh sensitivity issue, the study of mesh refinement was conducted to determine the suitable element size with less computational time. The maximum size of the element less than $50 \mathrm{~mm}$ was chosen. FE meshing of all three components is shown in Fig. 3.

\section{Model validation}

Generally, to verify the accuracy of the proposed finite element model, the predicted FE results were compared with the experimental tests performed by Mosoarca (2013). The comparisons between experimental results and $\mathrm{FE}$ analysis were presented in terms of the lateral load-tip displacement curves, and figures and tables describing the damage failure modes of analytical and experimental specimens. The established FE model and loading schemes for wall specimens are shown in Fig. 4. The verified FE results were discussed in the following sections. 
Fig. 3 Finite element meshing (Solid C3D8R) and Truss elements (T3D2)
Fig. 4 Loading and boundary conditions of wall specimens a SW1, b R-SW4, c R-SW8

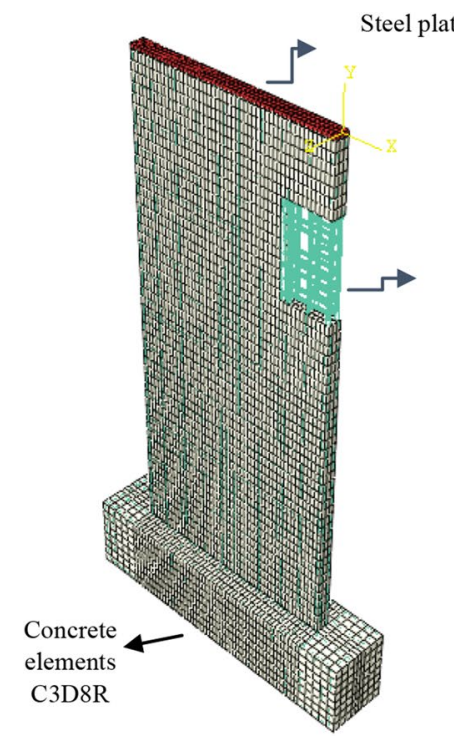

Steel plate C3D8R
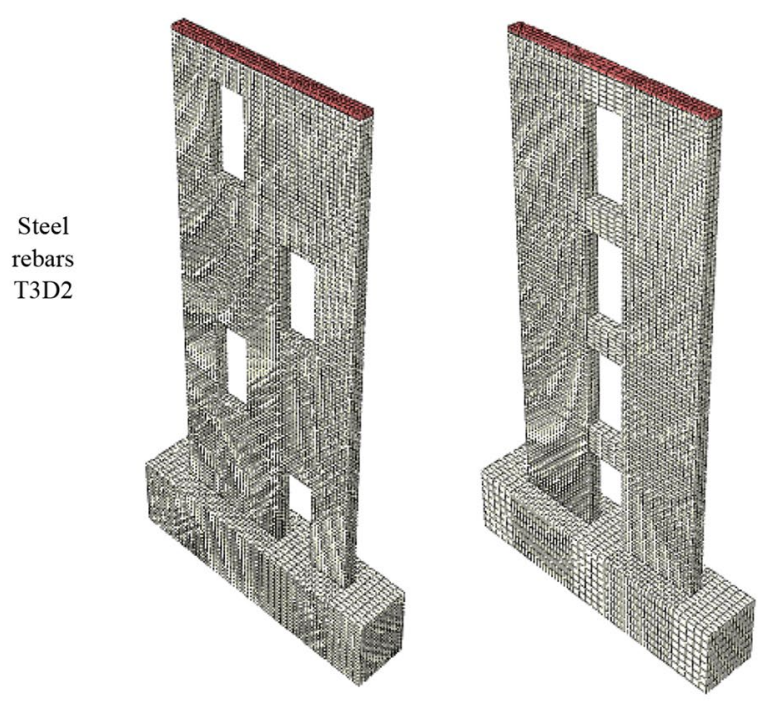

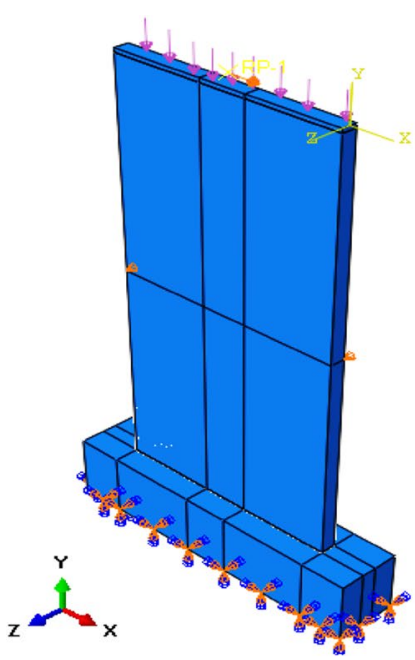

(a)

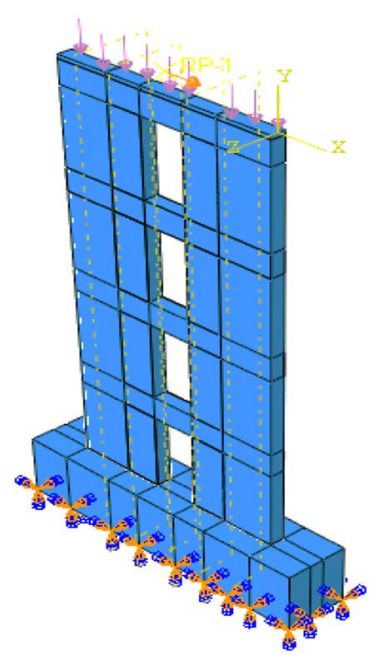

(b)

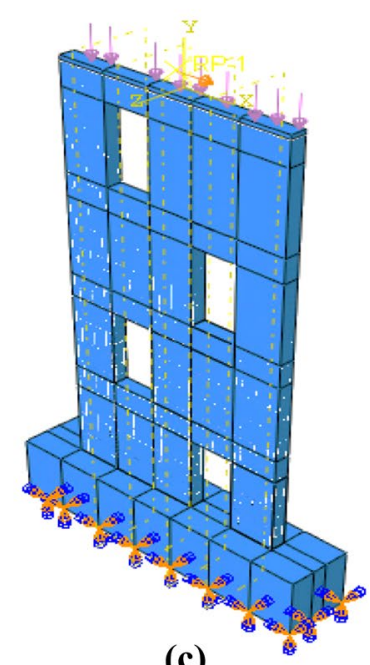

(c)

\section{Load-displacement response}

The simulated lateral load-top displacement curves by the proposed FE procedure are compared with the experimental results as shown in Fig. 5. It can be seen that the numerical results match the experimental results very well. As can be deduced, both FEM and experimental curves demonstrated similar trend behavior. For the control solid wall (C-S), the predicted ultimate load capacity was $106.40 \mathrm{kN}$ (within $1.1 \%$ accuracy) from the experimental ultimate load capacity of $114 \mathrm{kN}$. As expected, the structural capacity of the RC walls with openings was lower than those without openings. It can also be observed that the maximum lateral load capacity for wall specimens SW8 and SW4 was decreased by $39 \%$ and $24 \%$, compared to the control wall, respectively. Peak lateral loads and displacements predicted by the numerical simulation are obtained and compared in Table 4.

\section{Crack patterns and failure modes}

As seen in Figs. 6, 7 and 8, the simulated mode of failures for wall specimens obtained in this study using FE software was compared to that obtained experimentally. It can be seen that these failure modes are based on contours of mid-surface maximum principal strains. The failure modes for shear wall specimens were due to flexural cracks in the tension zone, concrete crushing at the wall toe and yielding of the steel reinforcement in the tension side.

The control specimen CW failed in a flexural manner; however, the first crack was observed at a lateral load of $54.4 \mathrm{kN}$ near the base of the wall on the tensile zone. 


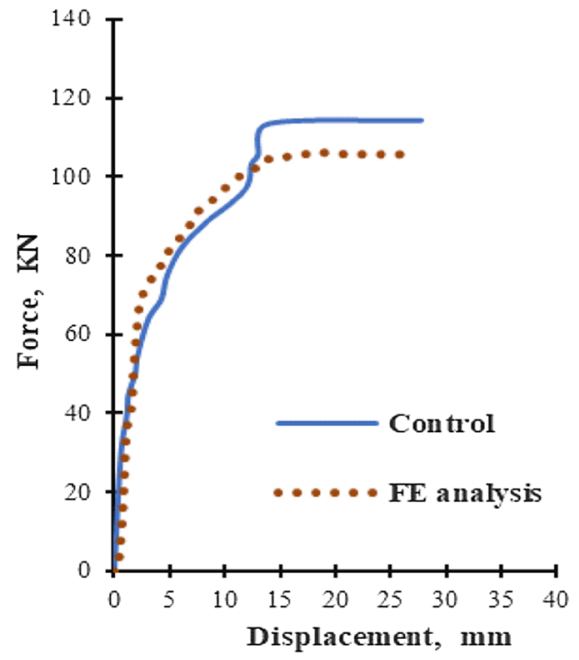

(a)

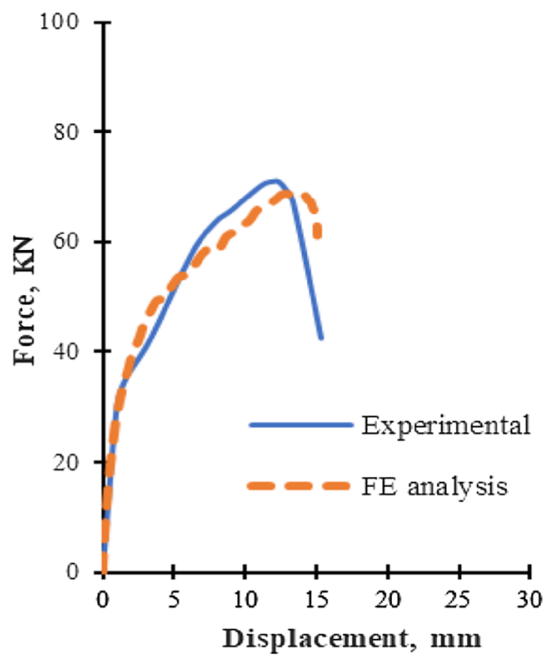

(b)

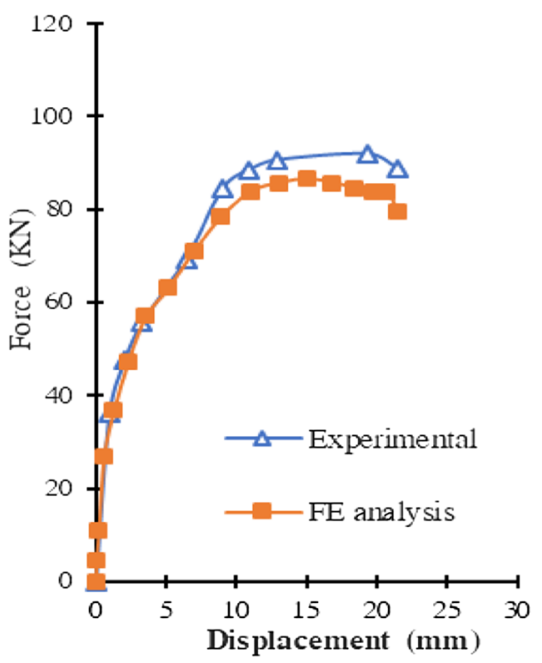

(c)

Fig. 5 Force-displacement curves from experimental and numerical analysis for wall specimens

Table 4 Numerical results versus Experimental results of wall specimens

\begin{tabular}{lllllll}
\hline Specimens & Experimental & & & Numerical (FEM) & $P_{\text {FEM }} / P_{\text {Exp } \%}$ \\
\cline { 2 - 3 } & Ultimate load, $P_{\mathrm{u}}$ & $\begin{array}{l}\text { Ultimate dis- } \\
\text { placement, } \Delta_{\mathrm{u}}\end{array}$ & & Ultimate load, $P_{\mathrm{u}}$ & $\begin{array}{c}\text { Ultimate dis- } \\
\text { placement, } \Delta_{\mathrm{u}}\end{array}$ \\
\hline Control & 113.63 & 14.00 & 106.38 & 18.35 & 93.62 \\
SW4 & 88.00 & 13.00 & & 86.56 & 15.00 & 98.36 \\
SW8 & 71.00 & 11.80 & & 69.10 & 13.60 & 97.32 \\
\hline
\end{tabular}
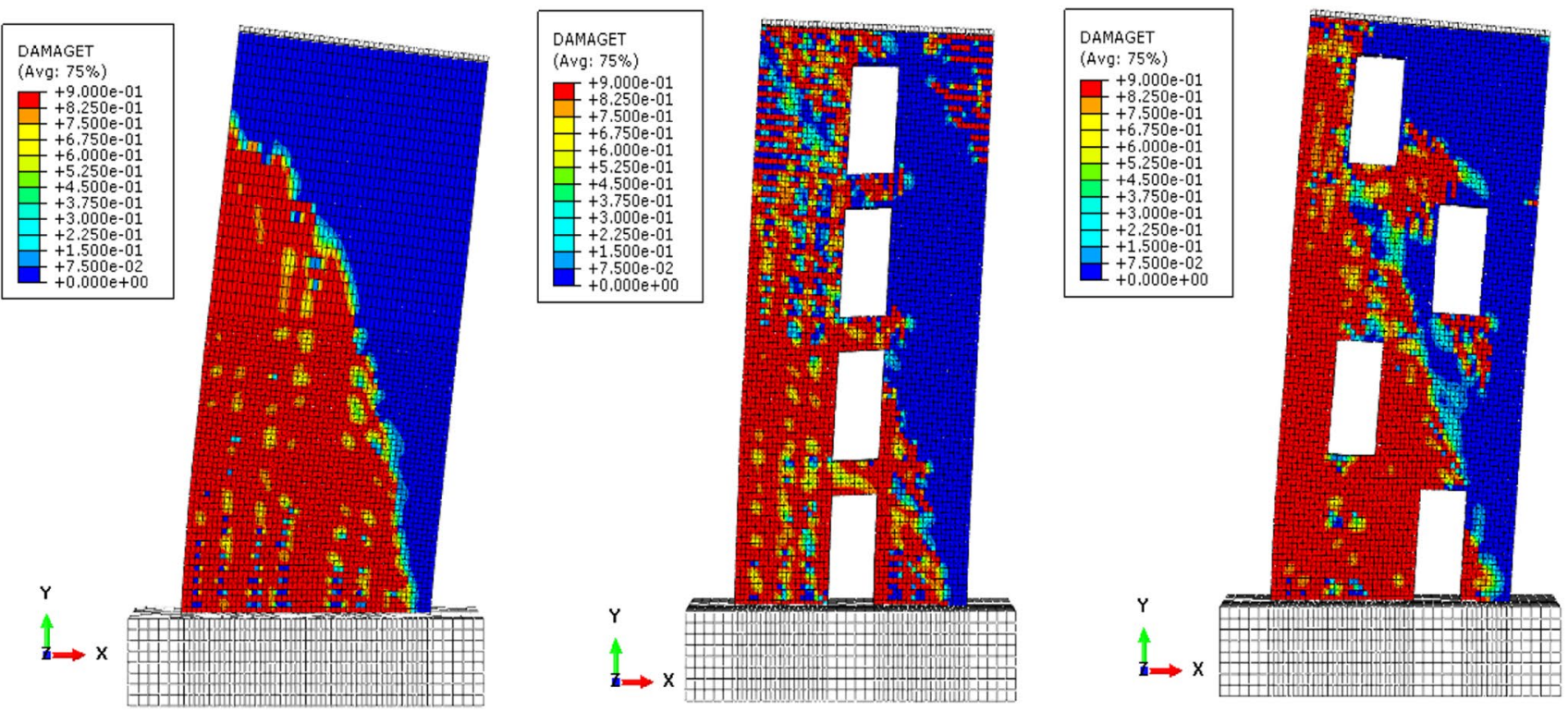

Fig. 6 Concrete failure damage modes of FE analysis for wall models (SW1 and SW4 and SW8) 
Fig. 7 Yielding of steel reinforcement at failure load for wall specimens (SW8) and (SW4)
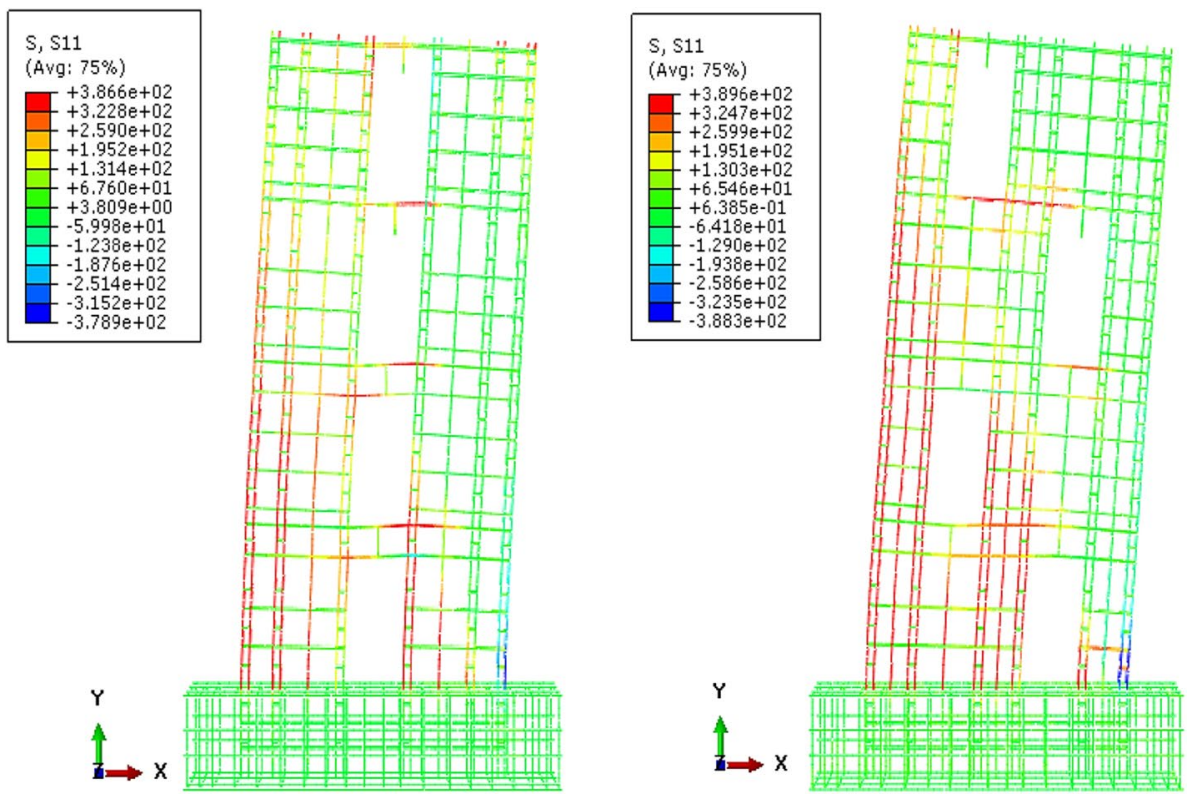

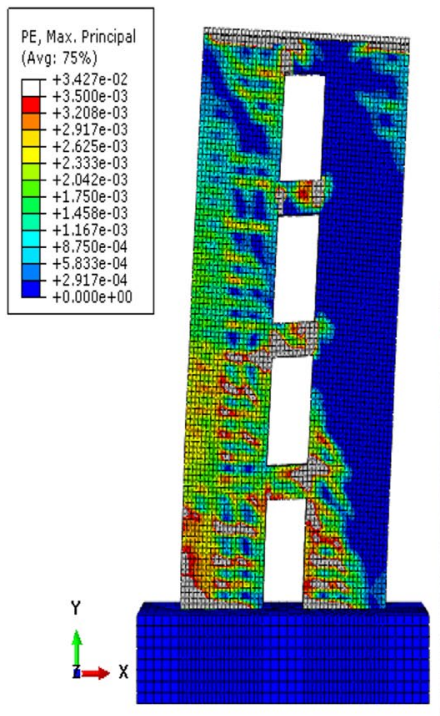

(a)

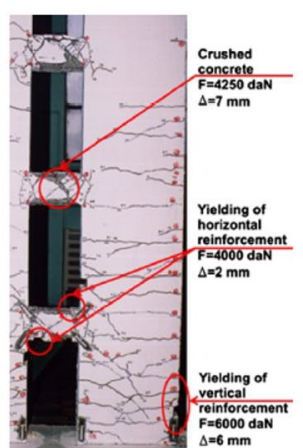

$F=6000 \mathrm{daN}$
$\Delta=6 \mathrm{~mm}$

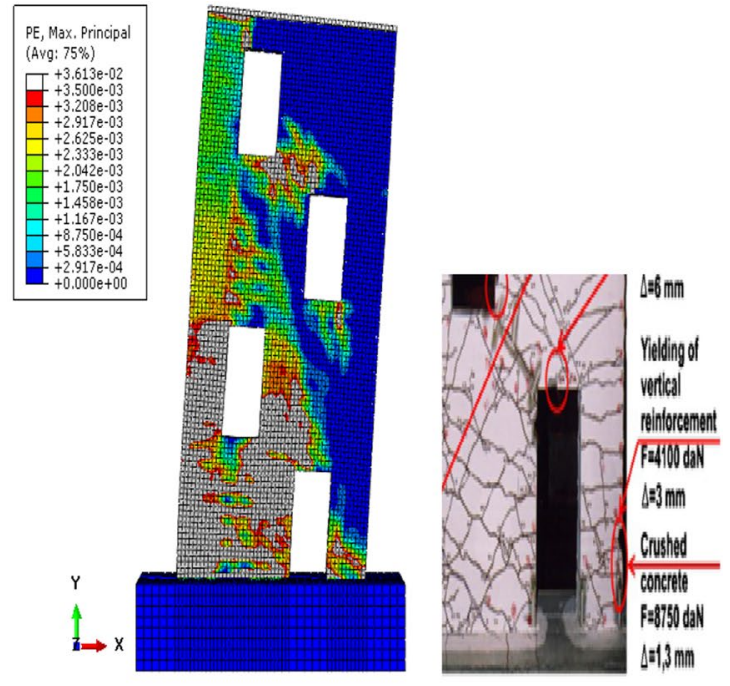

(b)

Fig. 8 Comparison of Max principal plastic concrete strain pattern between FE analysis and experimental results at failure load for walls a SW8 and b SW4

Diagonal cracks along the height of the wall were followed by horizontal flexural cracks. For specimen SW8, the bending cracks appeared at the base of the piers; however, the first crack was observed at $18.50 \mathrm{kN}$ with a lateral drift of $(0.02 \%)$. The first yield of the horizontal reinforcing steel bar was detected at the extremities of the coupling beam, at a load level of $61 \mathrm{kN}$. The corresponding displacement at this yield load was $8.62 \mathrm{~mm}$ and was followed by yielding the vertical reinforcement (at the base of the piers) at a load level of $58.52 \mathrm{kN}$ and the lateral drift was $8.1 \mathrm{~mm}(0.33 \%$ drift). For specimen SW4, the first crack was observed at the base of wall at a load level of $30.11 \mathrm{kN}$ and followed by inclined shear cracks between the openings. As shown in Fig. 8, it can be noted that in walls with staggered openings, the failure initiated by yielding of vertical steel rebar and followed by concrete crushing at the base of the small piers, after the concrete crushing of previous model, the vertical compressed rebars buckled. The first vertical steel rebar yielding was observed at $73.70 \mathrm{kN}$ lateral load at lateral drift $(0.33 \%)$ at the base of the small piers. 


\section{Parametric analysis}

In this section, three different parameters were studied and analyzed as follows: the retrofitting schemes of CFRP laminates, the number of CFRP layers and the concrete strength. These parameters had a major effect on the structural capacity of the RC walls with openings. The same CDP model was developed for all the cases to evaluate the wall behavior. The effects of three parameters on the wall strength are presented in the following sections.

\section{Strengthening schemes methodology}

The high tensile strength and performance of fibers used, carbon fiber-reinforced polymers (CFRP) laminates were used to investigate the efficiency of the flexure and shear strengthening of reinforced concrete elements. According to Demeter et al. (2010), the methodology of the retrofit schemes aimed to: (1) offer flexural capacity along the edges, (2) to provide confinement effect and (3) to increase the shear capacity of the wall, especially at the wall base. In this section, ten retrofitted walls were studied [R-SW4 (1-4) and R-SW8 (1-6)]. Wall specimens (R-SW8) were retrofitted using CFRP laminates with six different schemes. In Scheme 1, $1250 \mathrm{~mm} \times 150 \mathrm{~mm}$ (length $\times$ width) single-ply CFRP laminates oriented in the horizontal direction were applied to the top and bottom of each opening and applied on both wall sides. At the inner edge next to the openings, a 500-mm-long CFRP sheets were applied at each pier with fibers oriented in the vertical direction for flexural strengthening.

In Scheme 2, two different CFRP laminate configurations were used to increase the flexural strength of the left and right piers. For each pier, a 500.0-mm single-ply U-shaped single-ply unidirectional CFRP laminates were applied to the right pier that extended for a distance of $300.0 \mathrm{~mm}$ from the opening edge at both wall faces.

A 380.0-mm-wide single-ply U-shaped unidirectional CFRP laminates were applied at each spandrel to increase shear capacity. In Scheme 3, similar to scheme 2 but a 500.0-mm-long single-ply U-shaped unidirectional CFRP laminates were applied on the right pier that extended for a distance of $300.0 \mathrm{~mm}$ from wall opening edge at both wall faces. In Scheme 4, a 500.0-mm-length singleply U-shaped single-ply unidirectional CFRP laminates were applied through the door opening and fully wrapped around wall thickness at both wall sides and a 380.0-mmwide single-ply U-shaped single-ply unidirectional CFRP laminates were applied at each spandrel beam to increase shear capacity. In Scheme 5, a 500.0-mm-length singleply U-shaped single-ply unidirectional CFRP laminates were applied through the door opening and fully wrapped around wall thickness on the left pier and a 500.0-mmlength single-ply U-shaped single-ply unidirectional CFRP laminates were applied on the right pier that extended for a distance of $300.0 \mathrm{~mm}$ from wall opening edge at both wall faces. In Scheme 6, similar to scheme 4 but a $500.0-\mathrm{mm}$ length single-ply U-shaped single-ply unidirectional CFRP laminates were applied on the right pier that extended for a distance of $200.0 \mathrm{~mm}$ from the wall opening edge at both wall faces.

For wall specimens (R-SW4), four different retrofitting schemes were developed. A 500.0-mm-length single-ply U-shaped single-ply unidirectional CFRP laminates were applied on the right pier that extended for a distance of $240.0 \mathrm{~mm}$ from the wall opening edge at both wall faces, $1250 \mathrm{~mm} \times 150 \mathrm{~mm}$ (length $\times$ width) single-ply CFRP laminates oriented in the horizontal direction were applied to the top and bottom of each opening and applied on both wall faces and a 500-mm-length CFRP sheets were applied at each pier with fibers oriented in the vertical direction for flexural strengthening.

For shear retrofit, a 380.0-mm-wide single-ply U-shaped single-ply unidirectional CFRP laminates were applied at each wall spandrel beam to increase shear capacity, a 500.0-mm single-ply U-shaped single-ply unidirectional CFRP laminates were applied through the door opening and fully wrapped around wall thickness at both wall sides and a 500.0-mm single-ply U-shaped single-ply unidirectional CFRP laminates were applied on the right pier that extended for a distance of $490.0 \mathrm{~mm}$ from the wall opening edge at both wall faces. The detailed descriptions of applied CFRP configurations are given in Figs. 9 and 10.

\section{Effect of changing of CFRP schemes around openings}

Changing the CFRP laminates configurations had a major effect on the strengthened walls. The predicted FE results were presented in terms of the ultimate load carrying capacities, modes of failure, and principal strains in the concrete and CFRP laminates. Load-displacement curves for the retrofitted wall specimens are shown in Figs. 11 and 12. These figures indicate that the lateral displacement and lateral load carrying capacity were significantly increased. For the strengthened shear wall R-SW8, the measured ultimate load capacity was $79.40 \mathrm{kN}$; the figure shows that the second strengthening of the wall improved the lateral load capacity (about $11 \%$ ). The lateral load capacity and ultimate displacement for retrofitted specimens R-SW8-2 compared to SW8 increased by $11 \%$ than other strengthened specimens. As can be seen in this figure, CFRP laminates were partially wrapped around the wall piers and improved the lateral load capacity. Specimens R-SW8 failed due to crushing of 

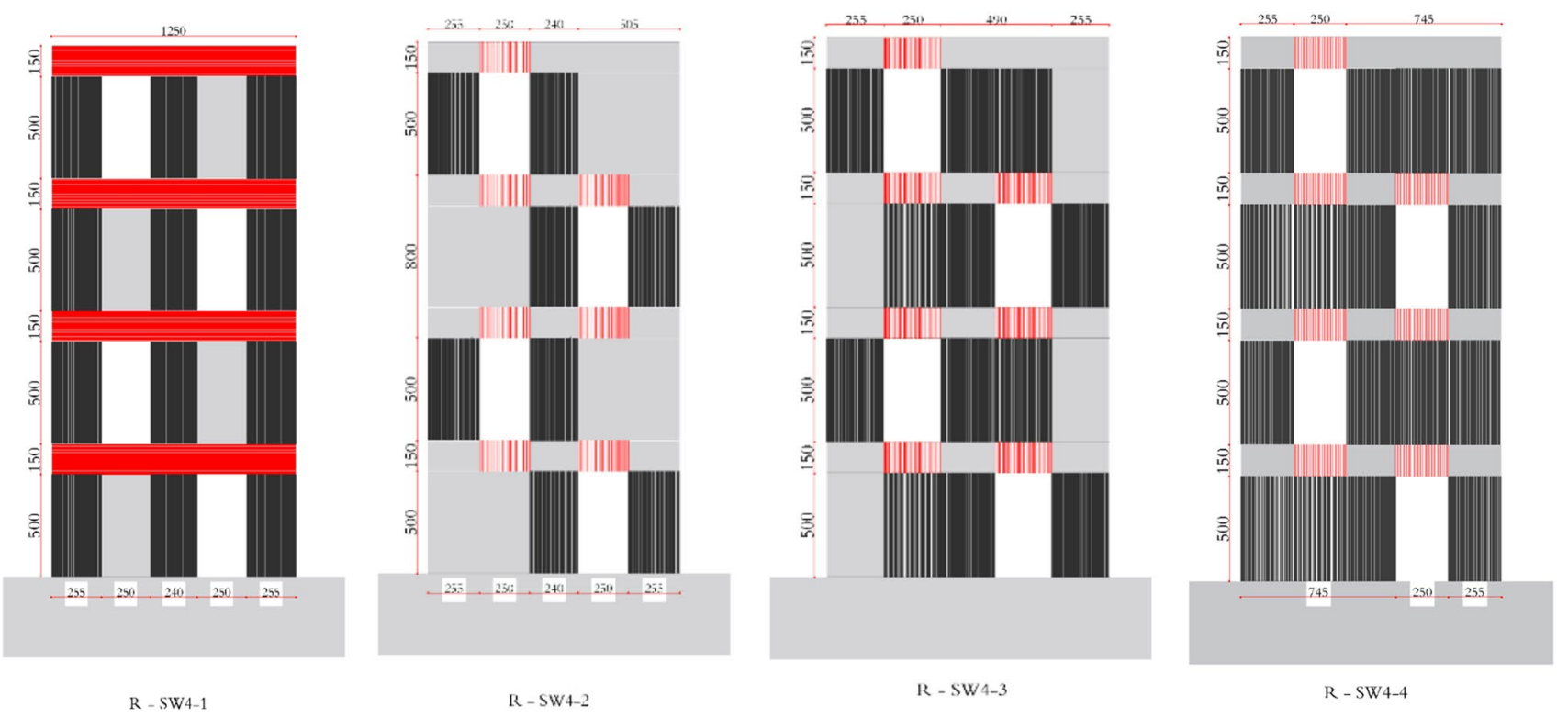

Fig. 9 CFRP Configurations of wall model (R-SW4)

concrete at the coupling beams of the wall. The load displacement curves of the shear wall R-SW4-1 showed that the lateral load capacity of R-SW4-1 was larger than that of corresponding control wall SW4 (about 7.8\%).

As can be seen in these figures, shear wall (R-SW4) failed due to forming Plastic hinge at the base of the wall and concrete cover was crushed over the base under lateral forces. Shear cracks were widened rapidly due to separation of CFRP laminates from the wall surface with the increase in lateral load. The lateral load capacity and ultimate displacement for retrofitted specimens R-SW4-3 compared to SW4 increased by $6.8 \%$. In this configuration, CFRP laminates were partially wrapped around the piers on the right side of the wall and effectively improved the wall capacity than wall R-SW4-2. It can be seen that when CFRP strips were symmetrically applied to both sides of the concrete wall, the lateral strength of shear was increased by $7.2 \%$. Although, the fully wrapped strips strengthening increases the shear capacity about $6.2 \%$. The shear wall R-SW4-1 has shown improvement of lateral load carrying capacity and lateral displacements were significantly increased $(7.8 \%$ and $25 \%$, respectively). From the previous results, shear walls R-SW8-2 and R-SW4-1 showed the most suitable performance in shear capacity. The percentages increase in the failure load due to strengthening using Carbon Fiber-Reinforced Polymer (CFRP) laminates are summarized in Table 5.

\section{Failure modes}

As shown in Figs. 13 and 14, as it shows that the FE results present the effect of CFRP configurations on the simulated modes of failure for RC walls that evaluated in this study using FE analysis. The failure modes for strengthened models were occurred due to flexural cracks in the tension zone and yielding of the steel rebars in the tension side.

Also, we can conclude that diagonal cracks along the height of the wall were followed by horizontal flexural cracks, in particular, extremely severe concrete fracture was observed at two piers near to the opening. The damage criterion used in this analysis was that failure occurred when concrete reached ultimate compressive strain or CFRP elements reached its ultimate tensile strain, which were corresponding to the failure mode of concrete crushing and FRP rupture. As seen in Fig. 15, it can be observed that the rebar strain reaches its yield strain before the strain in concrete reaches its failure strain. In other side, the strains distribution along the CFRP laminates was simulated. In Fig. 16, we can see that the compression strains of concrete near the edges of the walls and placed in the coupling beams reach its failure strain. In other side, the strains distribution along the CFRP laminates was simulated. As shown in Fig. 17, the failure is initiated by yielding of vertical steel rebars followed by rupture of CFRP laminates near the edges of the wall openings.

\section{Effect of the number of CFRP layers on strength}

To better understand the effect of increasing the number of CFRP layers on the strengthening of shear walls, according to our previous studies and common engineering applications, two and three layers of CFRP were selected for FE analysis to show how CFRP laminates change the control wall behavior. Figures 18 and 19 show the envelope curves 


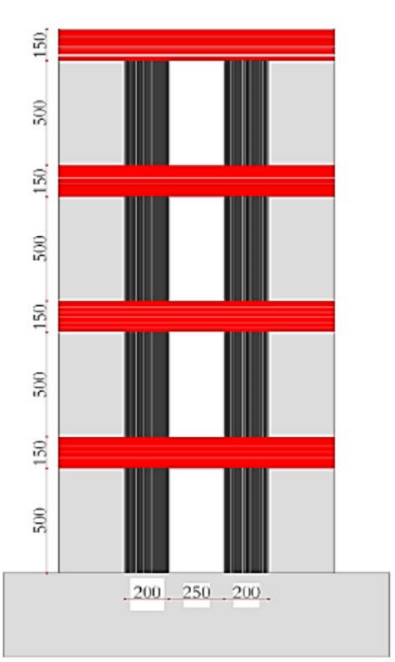

R - SW8-1
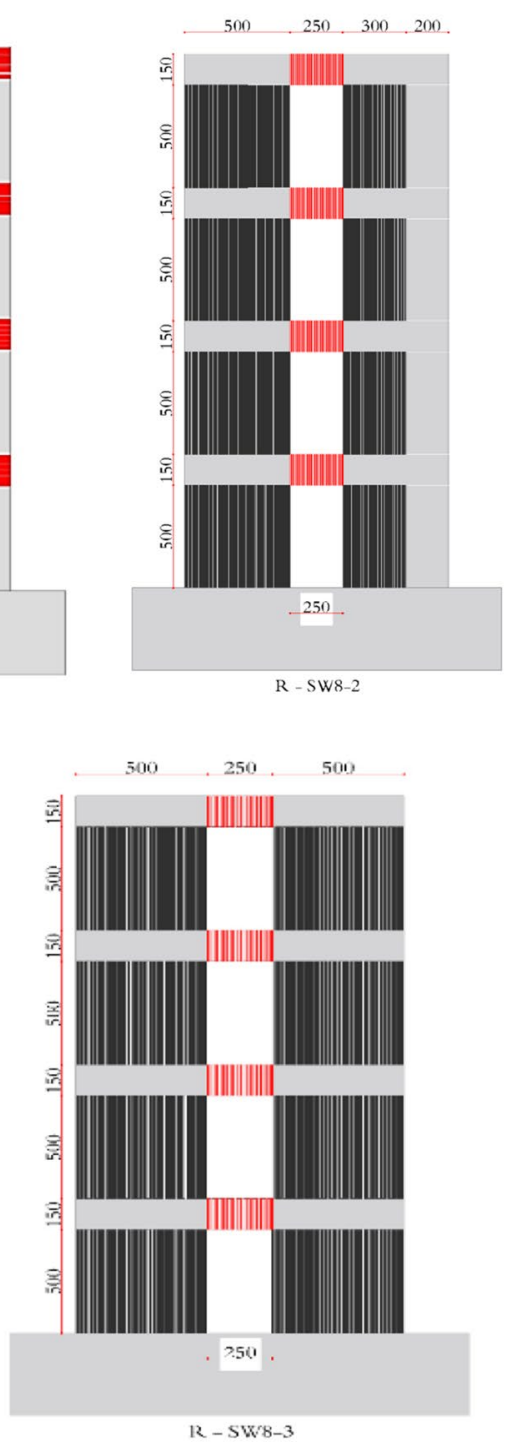

Fig. 10 CFRP Configurations of wall model (R-SW8)

of monotonic loading versus top displacement of the specimens. As a result, the thicker the CFRP is, the higher the ultimate load. The numerical analysis results of the strengthened walls are presented in Tables 6 and 7, respectively. The strength, ductility and energy dissipation of the wall specimens were effectively improved by strengthening and increasing the number of CFRP layers.

\section{Effect of concrete compressive strength}

In this section, the effect of changing the value of concrete strength $\left(f_{c}^{\prime}\right)$ on the seismic performance of FRP-retrofitted walls is investigated. The proposed concrete strength varies from 30 to $50 \mathrm{MPa}$ and from 50 to $70 \mathrm{MPa}$. In ABAQUS, the material properties of concrete in the FE model were defined in three different criteria as the initial
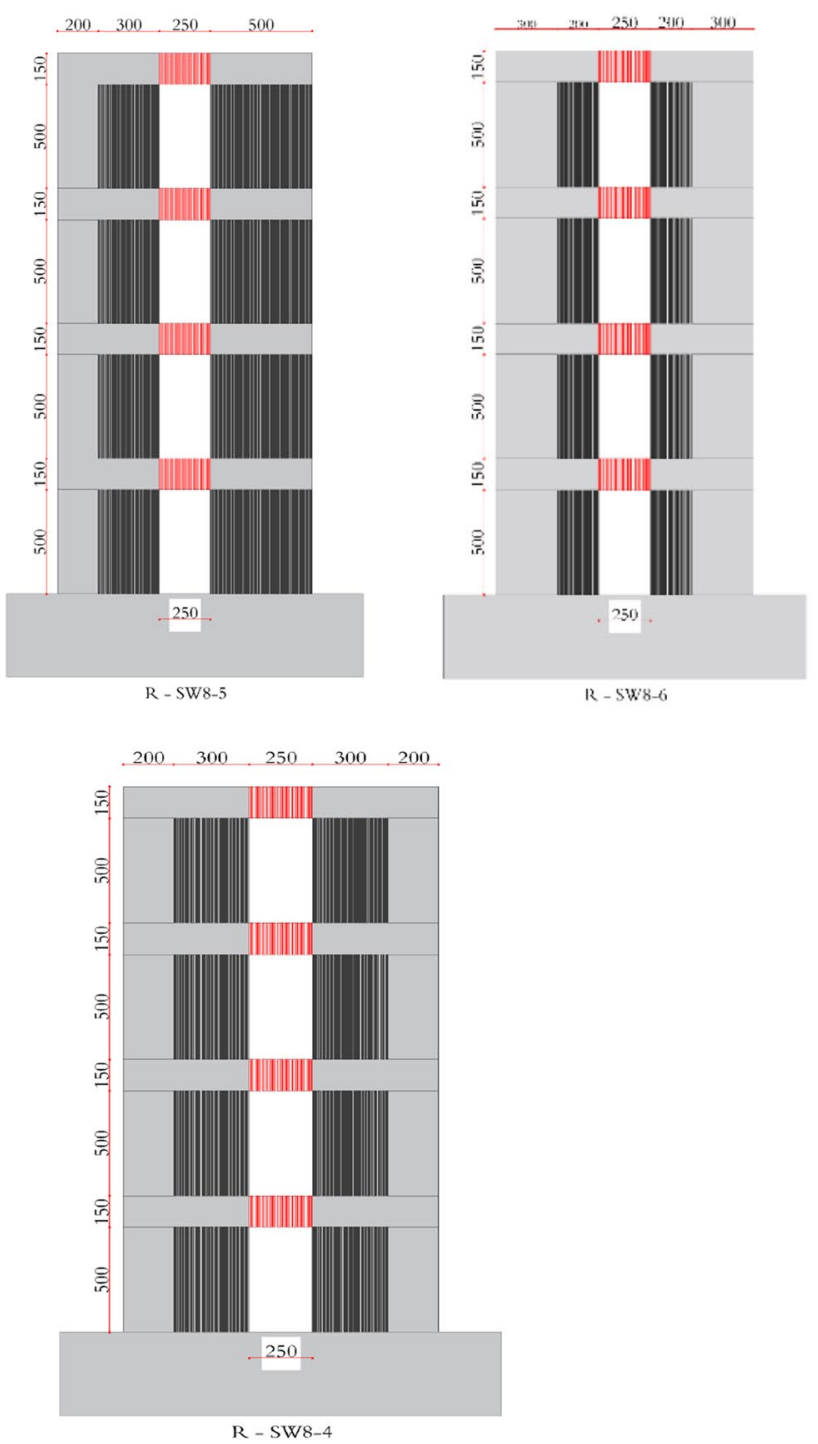

modulus, the stress-strain relationship and the concrete damaged plasticity model. To evaluate the understanding of the influence of $f_{c}^{\prime}$ on the seismic performance of FRPretrofitted shear walls, the FE model was analyzed with two different $f_{c}^{\prime}$ values. Additionally, a total of ten walls with various concrete compressive strengths are modeled and analyzed under lateral monotonic loading. To compare the results of FRP-retrofitted RC shear walls with those of the unretrofitted walls, the same loading history is used. Figures 20 and 21 show the influence of $f_{c}^{\prime}$ on the ultimate load carrying capacity of CFRP-retrofitted walls. From this figure, it can be concluded that increasing the concrete compressive strength does not improve the lateral load capacity for wall R-SW8, the measured ultimate load carrying capacity is about $26 \%$ lower for the wall (R-SW4) with $f_{c}^{\prime}=70 \mathrm{MPa}$ as compared to that of the 

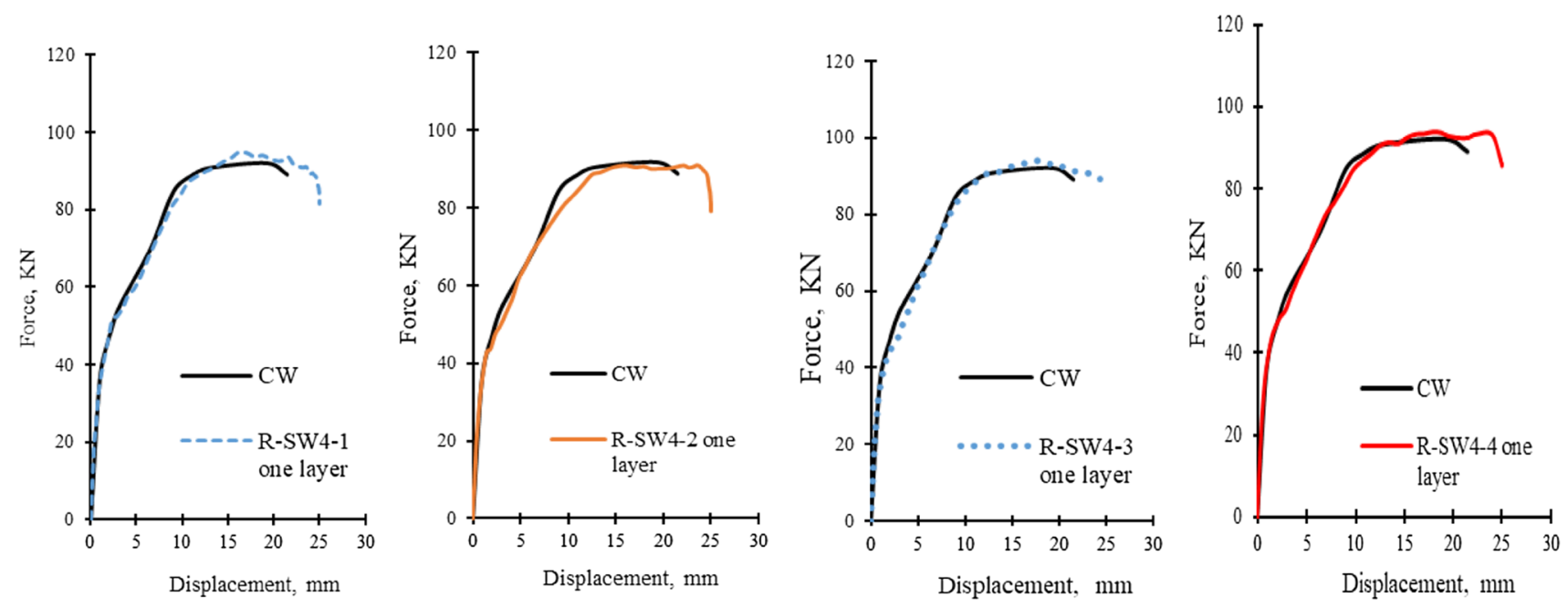

Fig. 11 Force-Displacement curve for wall specimens (R-SW4) wrapped by equivalent one layer of CFRP
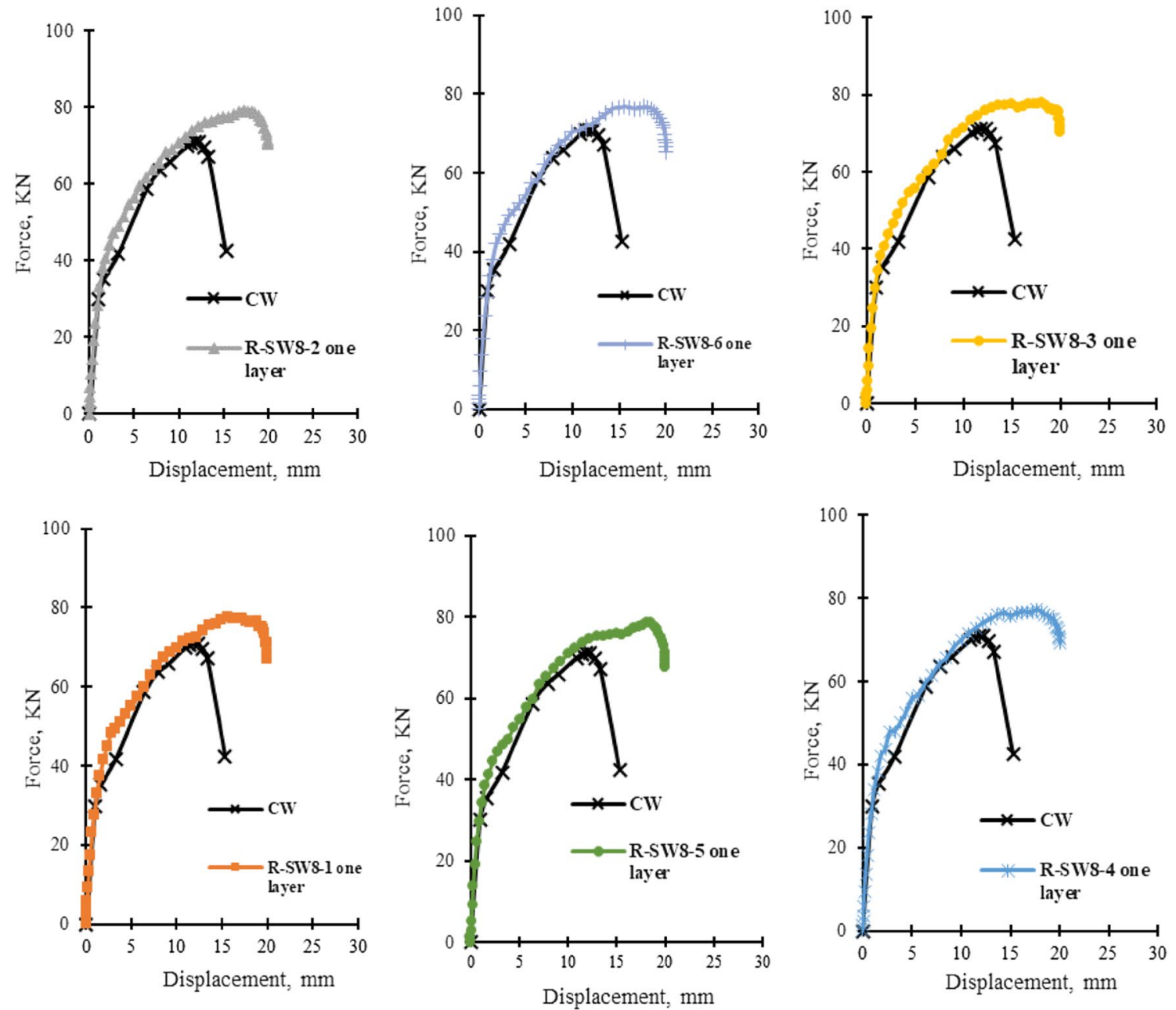

Fig. 12 Force-displacement curves for wall specimens (R-SW8) wrapped by equivalent one layer of CFRP 
Table 5 The percent of ultimate load compared to the control wall for retrofitted specimens (R-SW8) \& (R-SW4) with one layer of CFRP
Fig. 13 Effect of CFRP composite strengthening on failure damage pattern for strengthened walls a R-SW4-1, b R-SW4-2, c R-SW4-3 and d R-SW4-4

\begin{tabular}{llllllll}
\hline Model name & $\begin{array}{l}\text { Ultimate } \\
\text { load }(\mathrm{kN})\end{array}$ & $\begin{array}{l}\text { Ultimate } \\
\text { displacement } \\
(\mathrm{mm})\end{array}$ & $\begin{array}{l}\text { Percent- } \\
\text { age } \\
\text { increase }\end{array}$ & Model name & $\begin{array}{l}\text { Ultimate } \\
\text { load (kN) }\end{array}$ & $\begin{array}{l}\text { Ultimate } \\
\text { displacement } \\
(\mathrm{mm})\end{array}$ & $\begin{array}{l}\text { Percentage } \\
\text { increase }\end{array}$ \\
\hline Control & 71.00 & 12.80 & 0 & Control & 88.00 & 13.00 & 0.00 \\
R-SW8-1 & 77.74 & 15.60 & 8.67 & R-SW4-1 & 94.85 & 16.19 & 7.20 \\
R-SW8-2 & 79.40 & 17.20 & 10.85 & R-SW4-2 & 91.12 & 23.55 & 3.42 \\
R-SW8-3 & 77.80 & 18.14 & 8.74 & R-SW4-3 & 93.92 & 17.10 & 6.30 \\
R-SW8-4 & 77.17 & 17.71 & 8.00 & R-SW4-4 & 93.82 & 23.55 & 6.20 \\
R-SW8-5 & 78.62 & 18.14 & 9.70 & & & & \\
R-SW8-6 & 76.77 & 17.71 & 7.52 & & & & \\
\hline
\end{tabular}

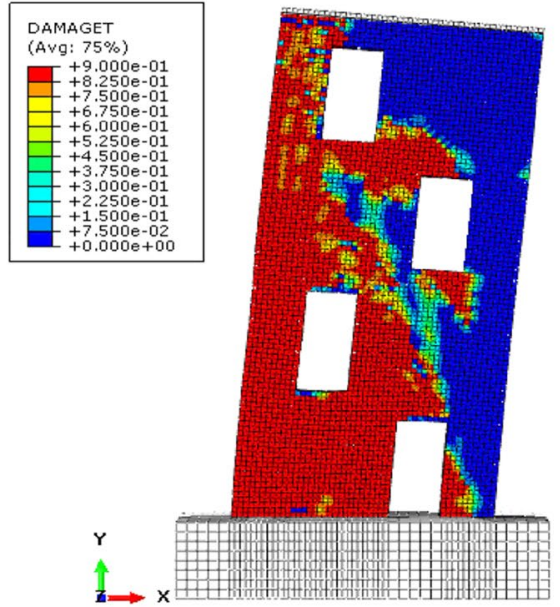

(a)

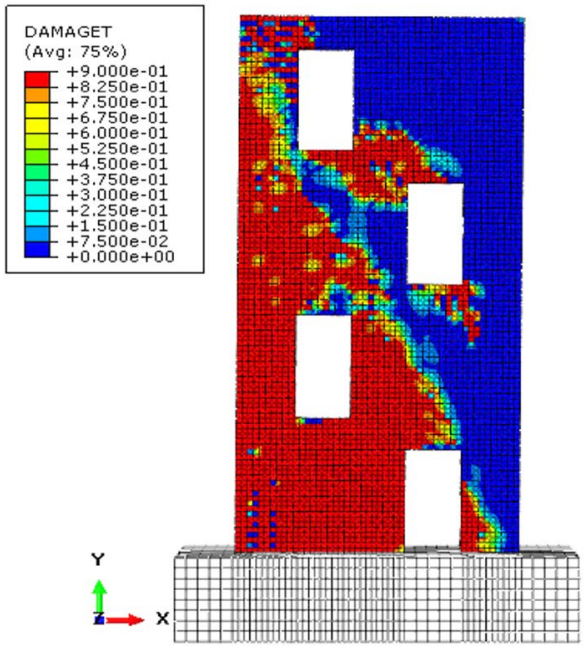

(c)

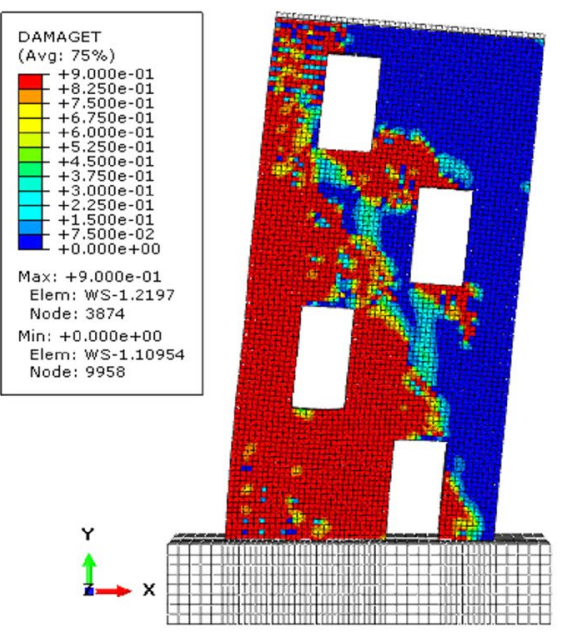

(b)
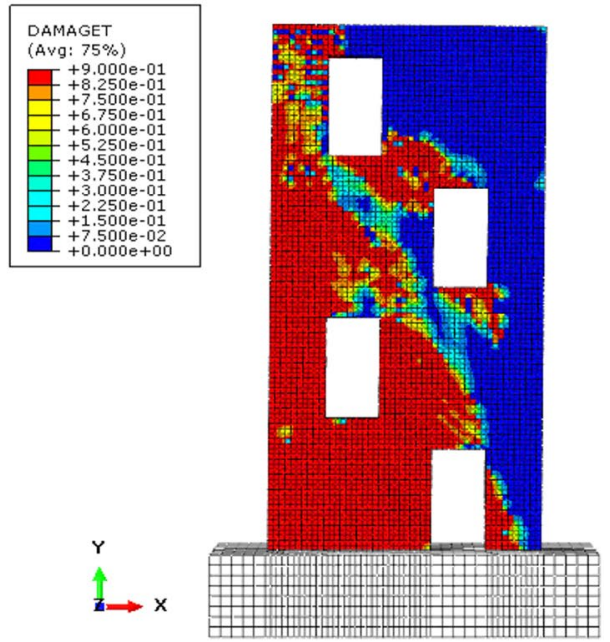

(d) wall with $f_{c}^{\prime}=50 \mathrm{MPa}$. The measured ultimate load carrying capacity is about 3.3\% higher for the wall (R-SW4) with $f_{c}^{\prime}=70 \mathrm{MPa}$ as compared to that of the wall with $f_{c}^{\prime}=30 \mathrm{MPa}$.

\section{Stiffness degradation}

As mentioned in Antoniades et al. (2007), the lateral stiffness degradation values for RC shear walls are well below those corresponding to their elastic properties, even at very low levels of load. Therefore, the secant stiffness of the 


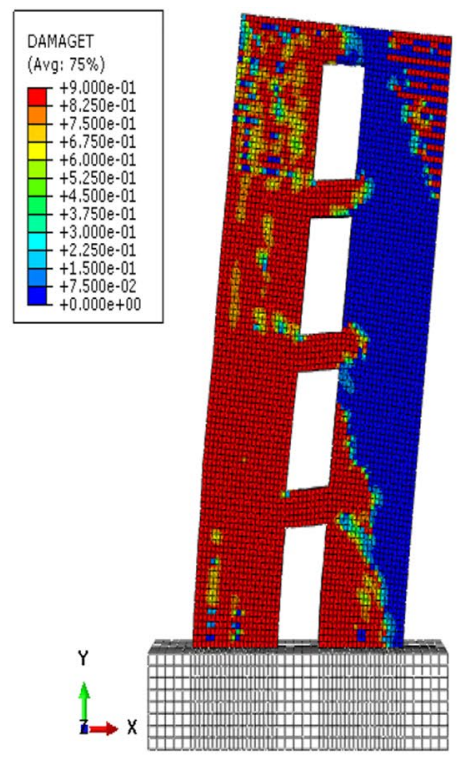

(a)

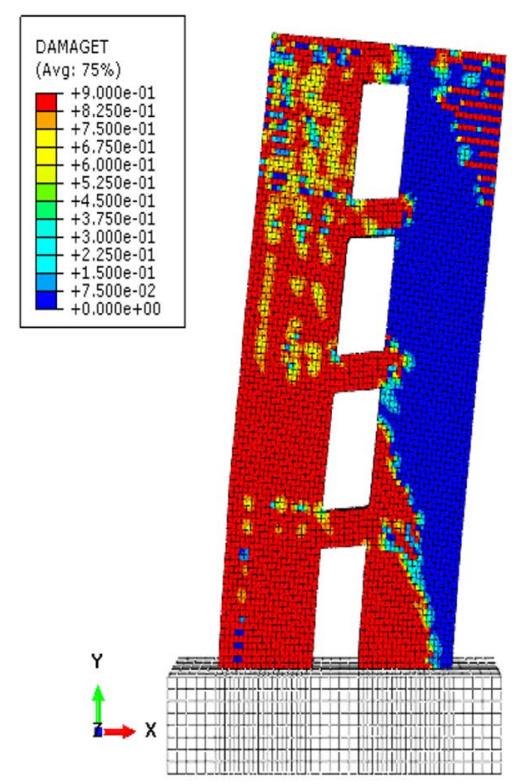

(d)

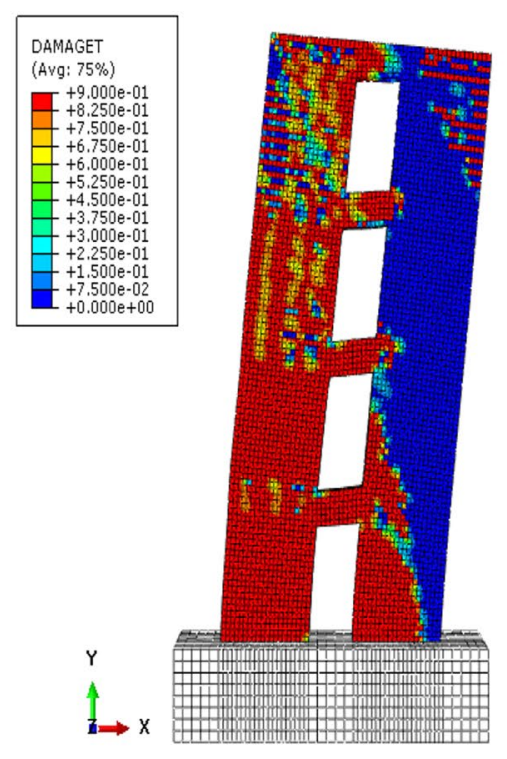

(b)

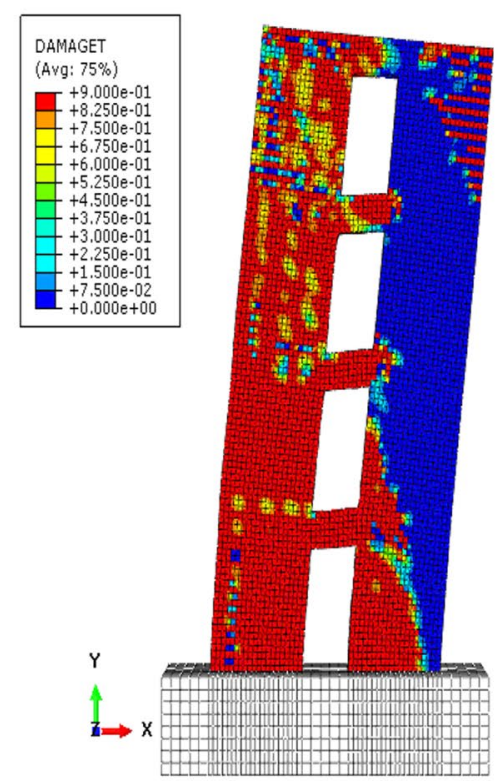

(e)

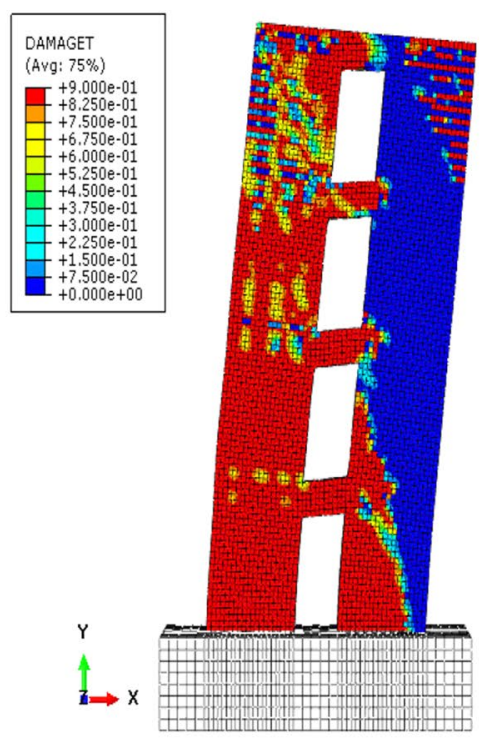

(c)

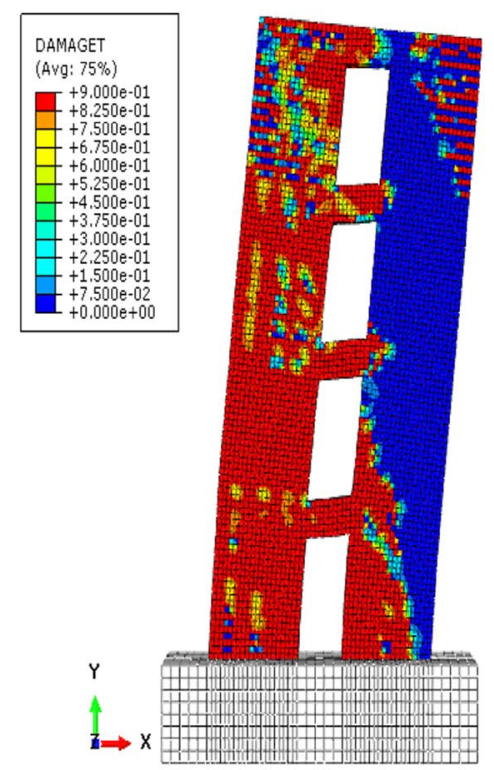

(f)

Fig. 14 Effect of CFRP composite strengthening on failure damage pattern for strengthened walls a R-SW8-1, b R-SW8-2, c R-SW8-3, d R-SW8-4, e R-SW8-5 and f R-SW8-6

numerical walls was defined as the ratio between the load and current displacement at each loading cycle. The calculation of the secant stiffness was developed in the following equation:

$K_{i}=\frac{\left|+F_{i}\right|+\left|-F_{i}\right|}{\left|+X_{i}\right|+\left|-X_{i}\right|}$

where $i$ is loading cycle number; $K_{i}, F_{i}$ and $X_{i}$ are secant stiffness, peak load, and displacement corresponding to the peak load for the loading cycle $i$, respectively. As shown in Fig. 22, the final secant stiffness of retrofitted specimens (R-SW8-1 to R-SW8-6) was about 5, 4.6, 4.3, 4.4, 4.3, and $4.3 \mathrm{kN} / \mathrm{mm}$, which decreased by about $11,18,22,22,23$ and $23 \%$ when compared with that of reference specimen SW8. In general, the strengthened specimens R-SW8 (1-6) had not only higher stiffness but also delayed stiffness degradation compared with that of reference specimen SW8. For specimens R-SW4 (1-4), the predicted secant stiffness values were about $6,4,5.5$ and $4 \mathrm{kN} / \mathrm{mm}$, which decreased 
Fig. 15 Contour of Max principal plastic concrete strain distribution in wall models a R-SW81, b R-SW8-2, c R-SW8-3, d R-SW8-4, e R-SW8-5 and f R-SW8-6

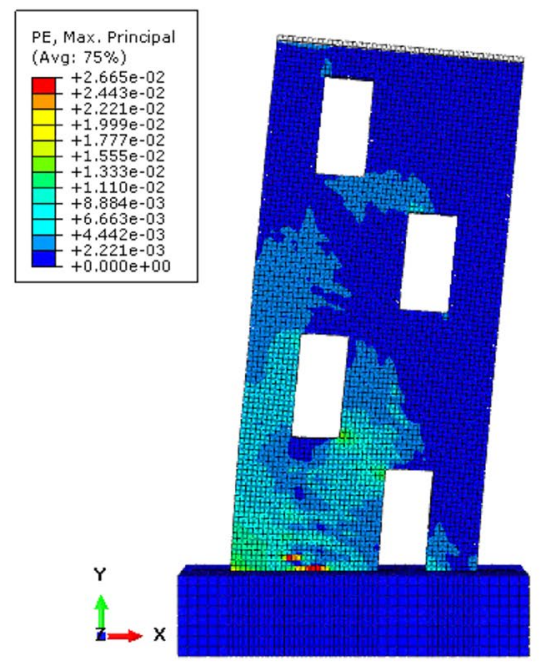

(a)

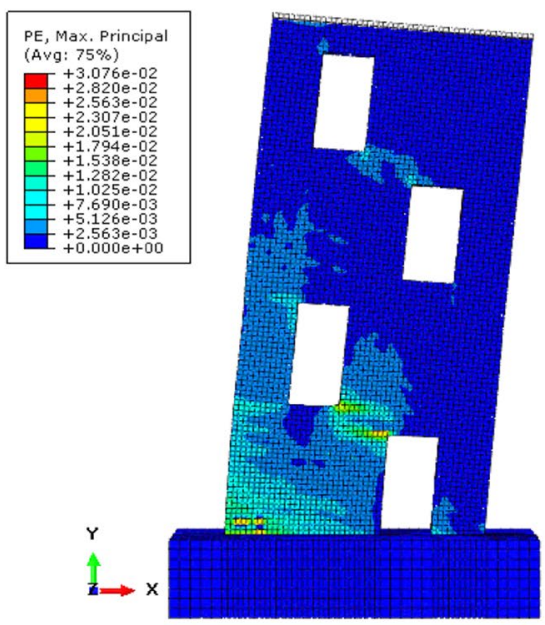

(c)

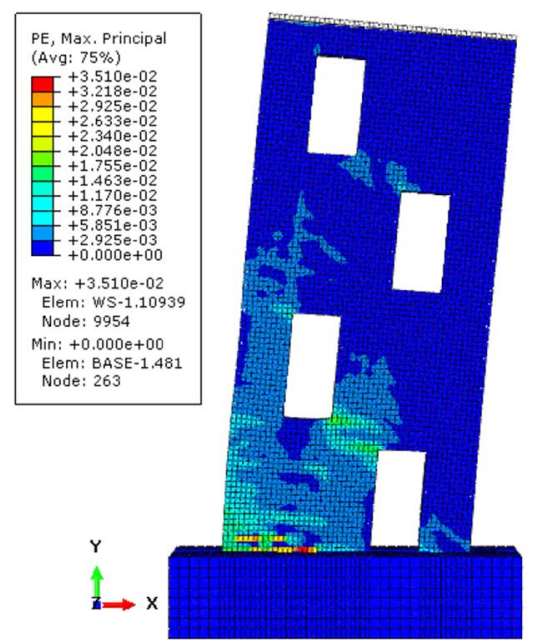

(b)

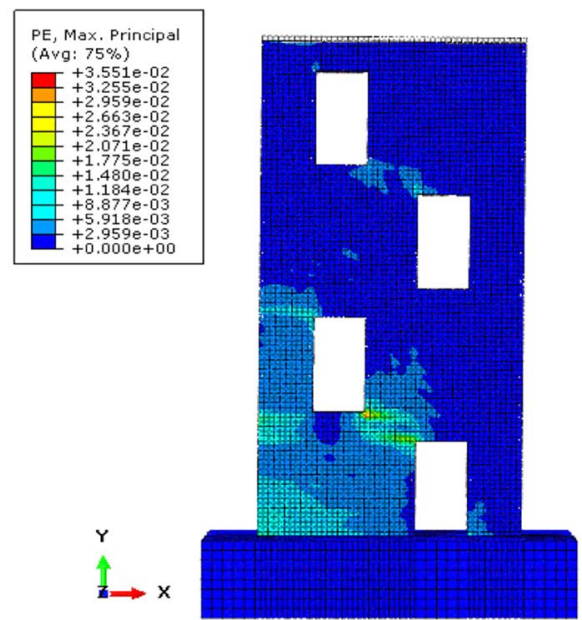

(d) by $13,43,19$ and $41 \%$ when compared with that of reference specimen SW4.

\section{Ductility}

Ductility is considered as a very important property in achieving the acceptance of FRP-reinforced concrete structures in practice [26]. Three parameters, namely yield displacement $\Delta_{\mathrm{y}}$, ultimate displacement $\Delta_{\mathrm{u}}$ and displacement ductility ratio $\mu$, were taken into consideration to evaluate the displacement ductility index. In present study, yield displacement $\left(\Delta_{\mathrm{y}}\right)$ corresponding to the load at yielding was evaluated according to the method reported by Park (1989). The ultimate/displacement $\left(\Delta_{\mathrm{u}}\right)$ was defined as displacement corresponding to $85 \%$ of peak load on descending branch of envelope curve.

The ductility index $\mu$ was defined as $\mu=\Delta_{\mathrm{u}} / \Delta_{\mathrm{y}}$. As shown in Table 8 , the displacement ductility ratios of specimens
R-SW8-1, R-SW8-2, R-SW8-3, R-SW8-4, R-SW8-5 and R-SW8-6 were 2.6, 2.6, 2.4, 2.6, 2.6 and 2.55, which were $37,37,26,40,39$ and $37 \%$ higher than that of reference specimen SW8, respectively. The displacement ductility ratios of specimens RSW4-1, R-SW4-2 and R-SW4-4 were $3.2,2.8$ and 2.7 which were 25,11 and $4.7 \%$ higher than that of reference specimen SW4, respectively. Although the displacement ductility ratio of specimen R-SW4-3 was not clearly increased, the yield and ultimate displacements were clearly improved compared with those of the reference specimen.

\section{Energy dissipation}

Park (1989) has investigated the energy dissipation mechanism of slender reinforced concrete structural elements subjected to reversed cyclic lateral loading and reported that the energy dissipation capacity of reinforced concrete 


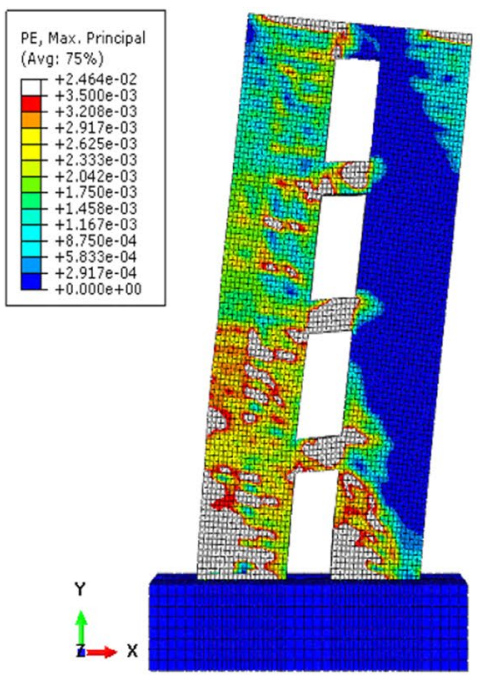

(a)

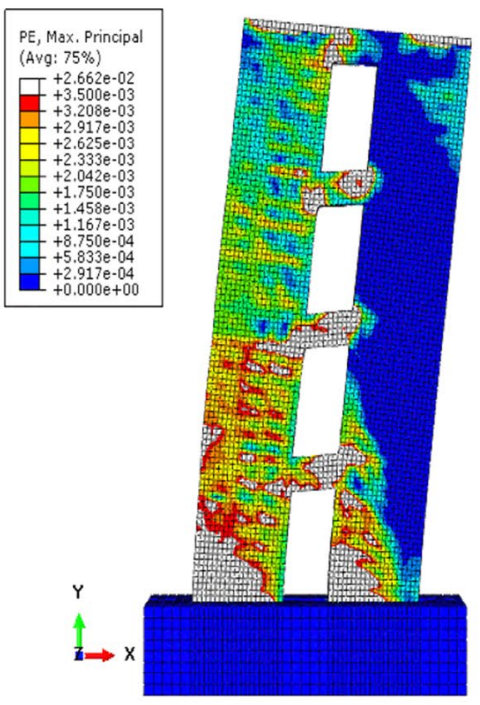

(d)

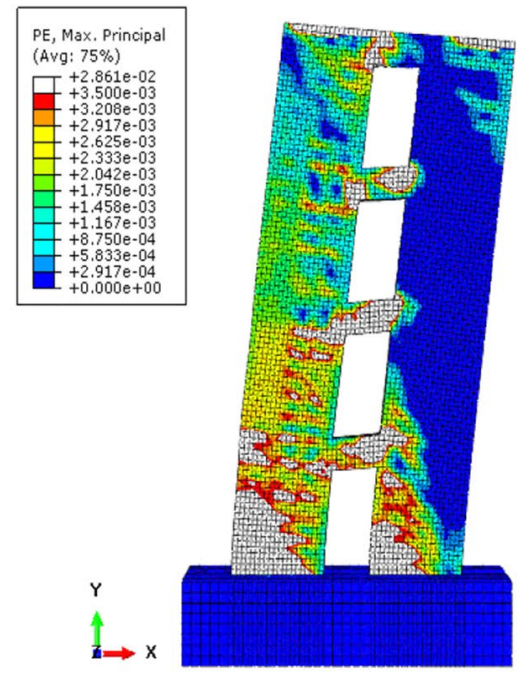

(b)

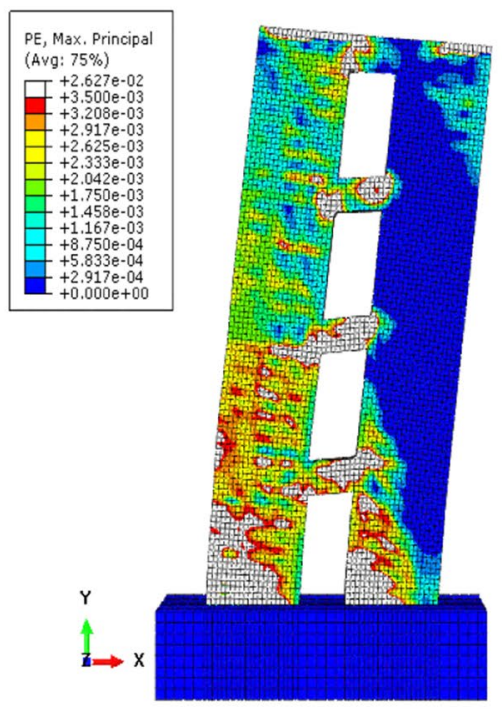

(e)

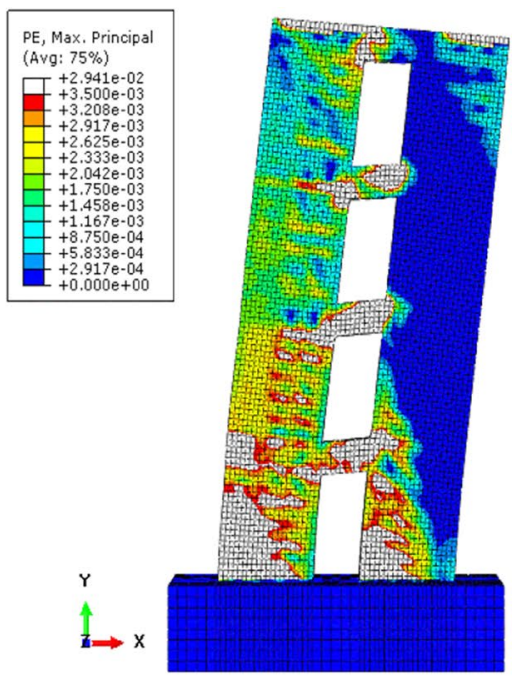

(c)

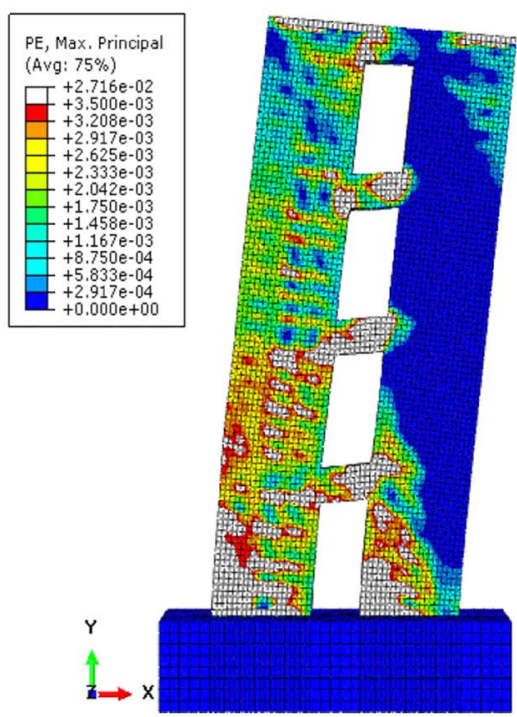

(f)

Fig. 16 Contour of Max principal plastic concrete strain distribution in wall models a R-SW4-1, b R-SW4-2, c R-SW4-3 and d R-SW4-4

member is significantly influenced by different design parameters such as: reinforcement ratio, reinforcement arrangement, magnitude of inelastic deformation and magnitude of axial compressive load. Energy dissipation is described as basic structural property of RC members when subjected to seismic loads. The area under the force-displacement curves can be used as a measure of the energy dissipation capacities (Ghobarah and Khalil 2004). According to Nguyen-Minh et al. (2018), the energy absorption capacity $\left(E_{\mathrm{b}}\right)$ was estimated by calculating the area under the load-displacement curves until the maximum loads. Table 8 shows that the final dissipated energy absorption capacity of specimens SW8 and
R-SW8 (1-6) was 840, 1258, 1275, 1172, 1247, 1263 and $1239 \mathrm{kN} . \mathrm{mm}$, which increased by 50, 52, 40, 48, 50 and $47 \%$ when compared with that of reference SW8, respectively. The energy absorption capacity of specimens SW4 and R-SW4 (1-4) was 1630, 1953, 1900, 1884, and 1952 kN.mm, which increased by about $20,17,16$, and $20 \%$ when compared with that of reference SW4, respectively. Energy absorption capacity of the retrofitted specimens was significantly higher than that of the reference specimen SW8 as seen in Fig. 22. As previously mentioned, the benefit of strengthening of the RC walls using CFRP composite laminates was to help RC shear walls sustain further inelastic deformations without collapse. 

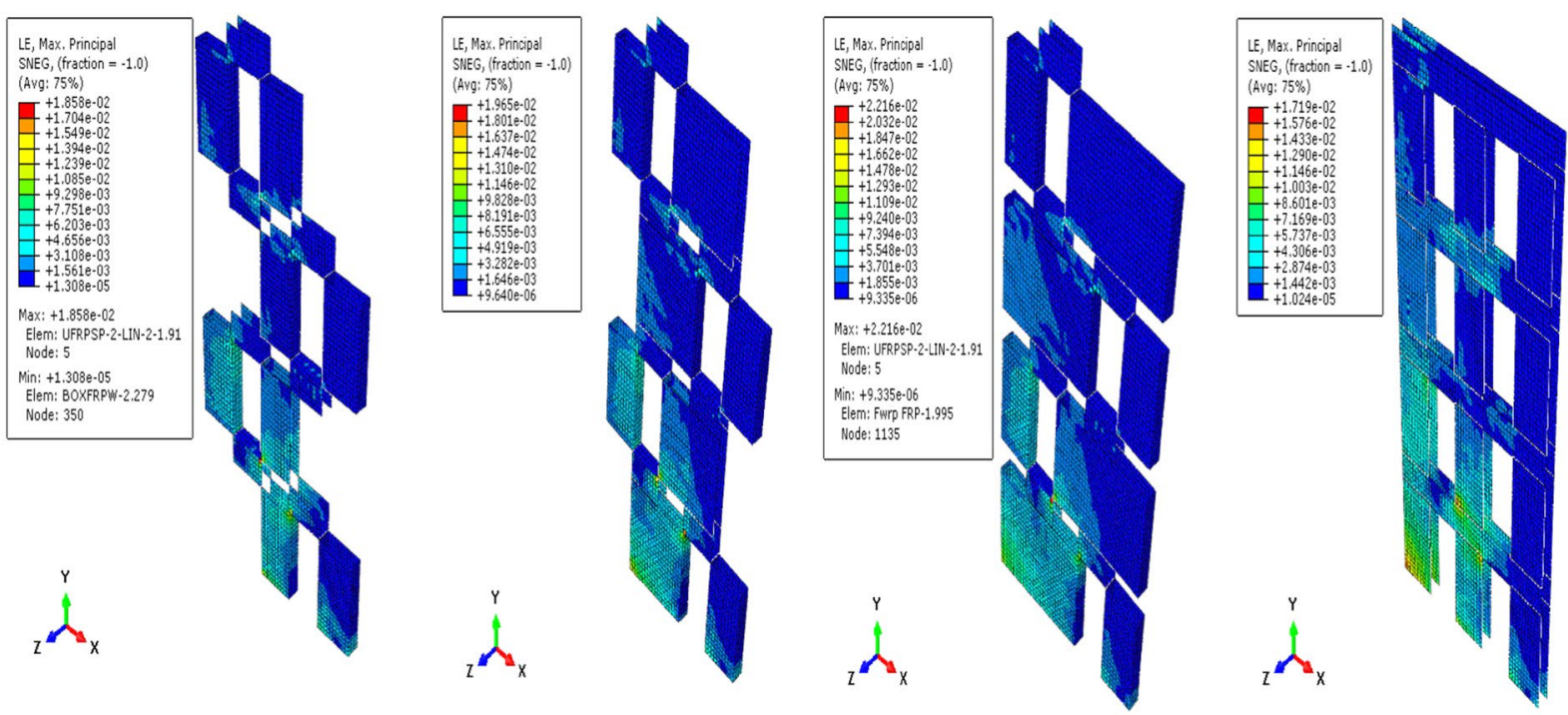

(a)
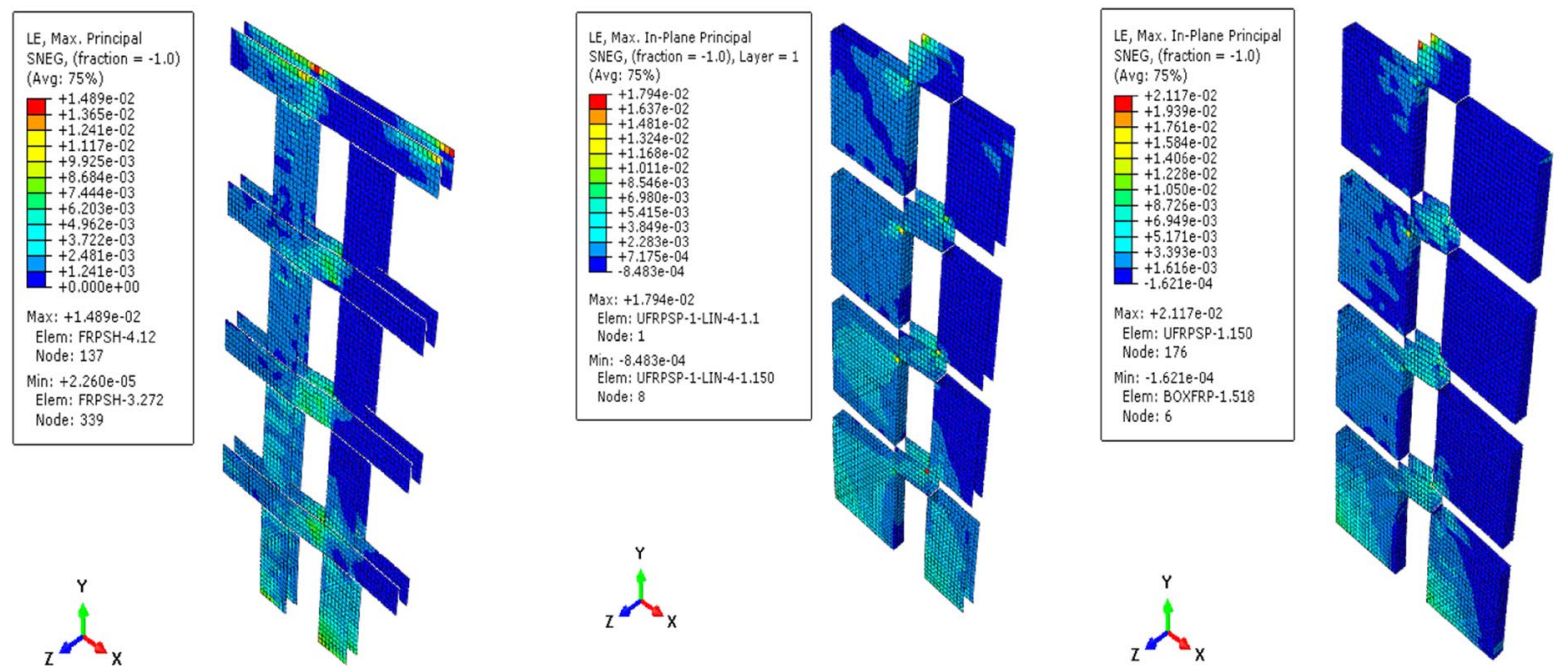

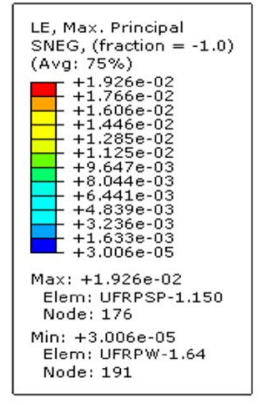

${ }_{z} \stackrel{x}{r}$
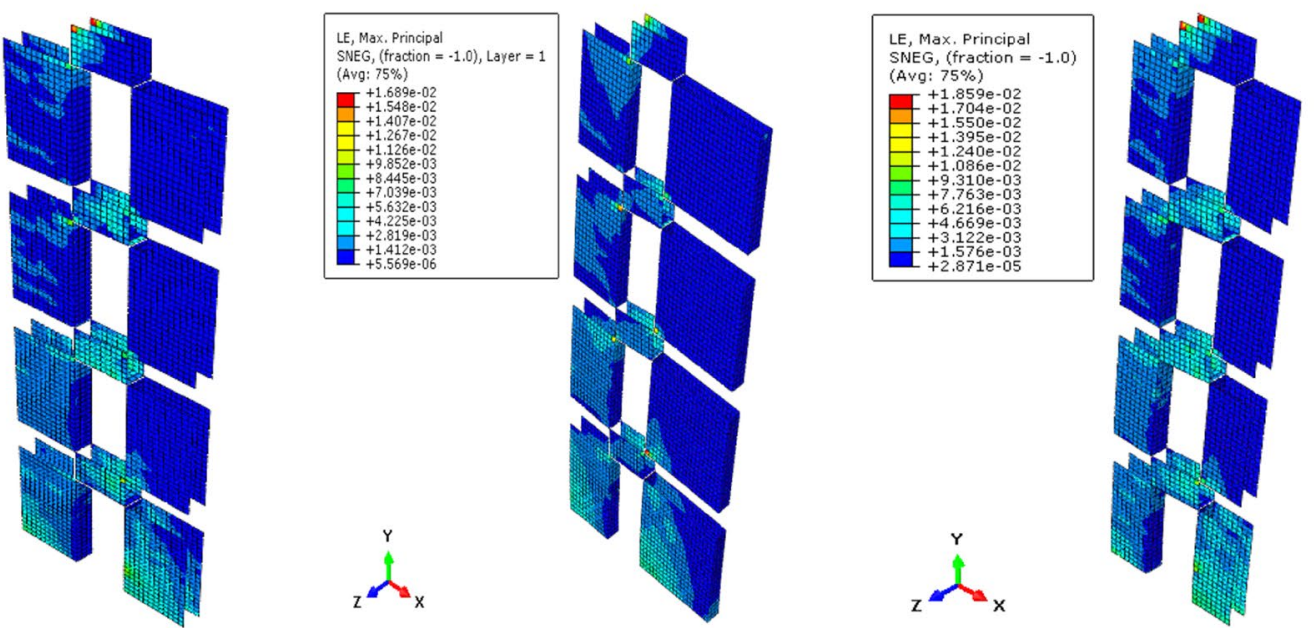

(b)

Fig. 17 Max principal Strain distribution in the CFRP of wall models a R-SW4, b R-SW8 
Fig. 18 Force-displacement curve for wall specimens (R-SW4) wrapped by equivalent two and three layers of CFRP

Fig. 19 Force-displacement curve for wall specimens (R-SW8) wrapped by equivalent two and three layers of CFRP
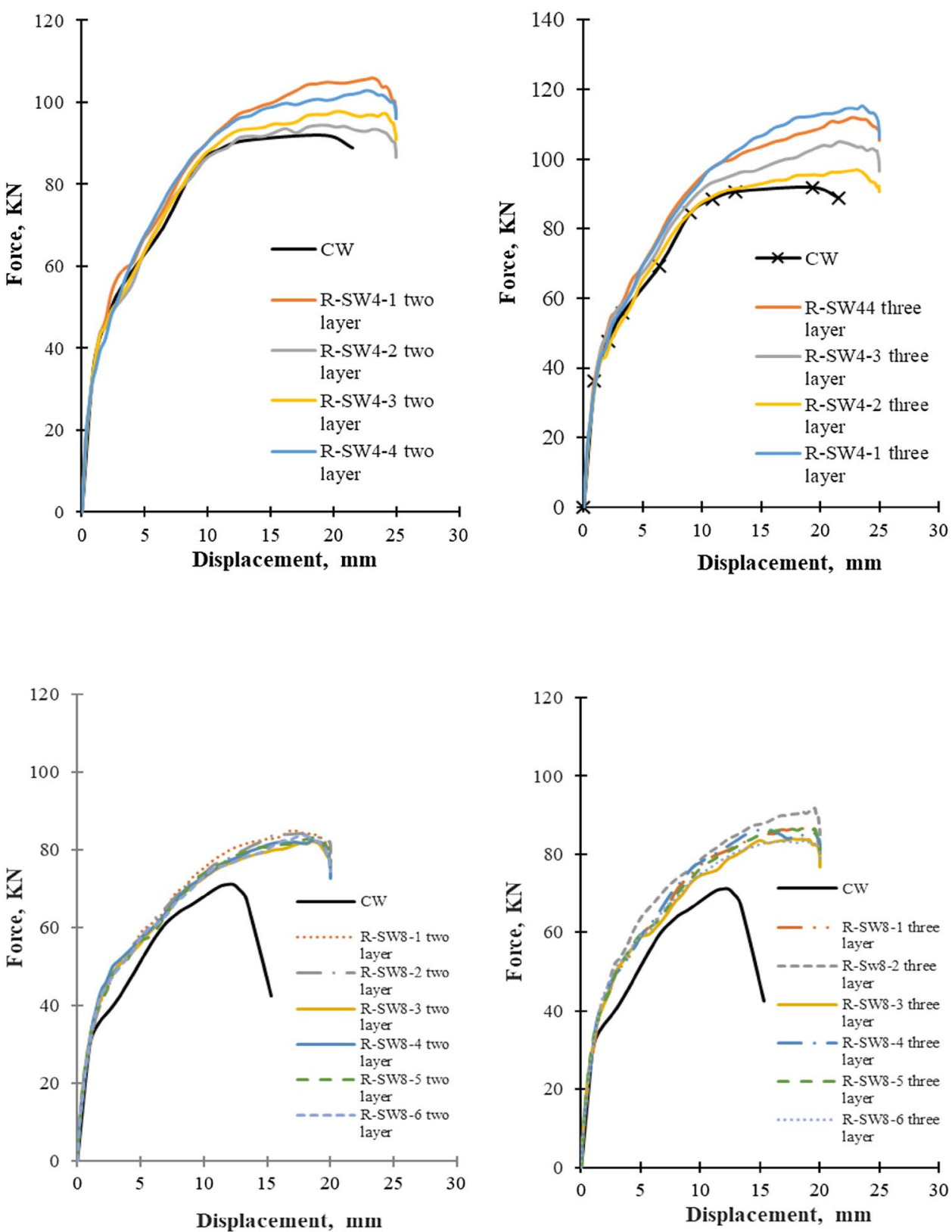

Table 6 The percent of ultimate load to the control one for retrofitted specimens (R-SW8) with number of CFRP layers

\begin{tabular}{|c|c|c|c|c|c|c|}
\hline \multirow[t]{2}{*}{ Specimens } & \multicolumn{2}{|l|}{ Two layers, $n=2$} & \multicolumn{2}{|l|}{ Three layers, $n=3$} & \multirow{2}{*}{$\begin{array}{l}\text { Percentage } \\
\text { increase, } n=2\end{array}$} & \multirow{2}{*}{$\begin{array}{l}\text { Percentage } \\
\text { increase, } \\
n=3\end{array}$} \\
\hline & Ultimate load, $P_{\mathrm{u}}$ & $\begin{array}{l}\text { Ultimate displace- } \\
\text { ment, } \Delta_{\mathrm{u}}\end{array}$ & Ultimate load, $P_{\mathrm{u}}$ & $\begin{array}{l}\text { Ultimate displace- } \\
\text { ment, } \Delta_{\mathrm{u}}\end{array}$ & & \\
\hline Control & 71.00 & 12.80 & 71.00 & 12.80 & 0 & 0 \\
\hline R-SW8-1 & 84.83 & 17.25 & 87.05 & 19.13 & 16.30 & 18.44 \\
\hline R-SW8-2 & 84.16 & 17.71 & 91.73 & 19.56 & 15.64 & 22.60 \\
\hline R-SW8-3 & 82.10 & 18.51 & 83.96 & 17.71 & 13.52 & 15.44 \\
\hline R-SW8-4 & 82.47 & 18.51 & 86.36 & 15.60 & 13.91 & 17.80 \\
\hline R-SW8-5 & 83.20 & 18.84 & 86.64 & 18.51 & 14.70 & 18.10 \\
\hline R-SW8-6 & 83.65 & 17.71 & 83.32 & 18.51 & 15.12 & 14.78 \\
\hline
\end{tabular}


Table 7 The percent of ultimate load to the control one for retrofitted specimens (R-SW4) with number of CFRP layers

\begin{tabular}{|c|c|c|c|c|c|c|}
\hline \multirow[t]{2}{*}{ Specimen } & \multicolumn{2}{|l|}{ Two layers, $n=2$} & \multicolumn{2}{|l|}{ Three layers, $n=3$} & \multirow{2}{*}{$\begin{array}{l}\text { Percentage } \\
\text { increase, } n=2\end{array}$} & \multirow{2}{*}{$\begin{array}{l}\text { Percentage } \\
\text { increase, } n=3\end{array}$} \\
\hline & Ultimate load, $P_{\mathrm{u}}$ & $\begin{array}{l}\text { Ultimate displace- } \\
\text { ment, } \Delta_{\mathrm{u}}\end{array}$ & Ultimate load, $P_{\mathrm{u}}$ & $\begin{array}{l}\text { Ultimate displace- } \\
\text { ment, } \Delta_{\mathrm{u}}\end{array}$ & & \\
\hline Control & 88.00 & 13.00 & 88.00 & 13.00 & 0 & 0 \\
\hline R-SW4-1 & 106.00 & 23.10 & 115.25 & 23.55 & 16.98 & 23.64 \\
\hline R-SW4-2 & 94.54 & 19.50 & 97.13 & 23.14 & 6.92 & 9.40 \\
\hline R-SW4-3 & 97.17 & 24.21 & 105.14 & 21.56 & 9.44 & 16.30 \\
\hline R-SW4-4 & 102.83 & 22.67 & 112.06 & 22.67 & 14.42 & 21.47 \\
\hline
\end{tabular}

Fig. 20 Effect of $f_{c}^{\prime}$ on the FRPretrofitted wall's ultimate load carrying capacity (R-SW4)
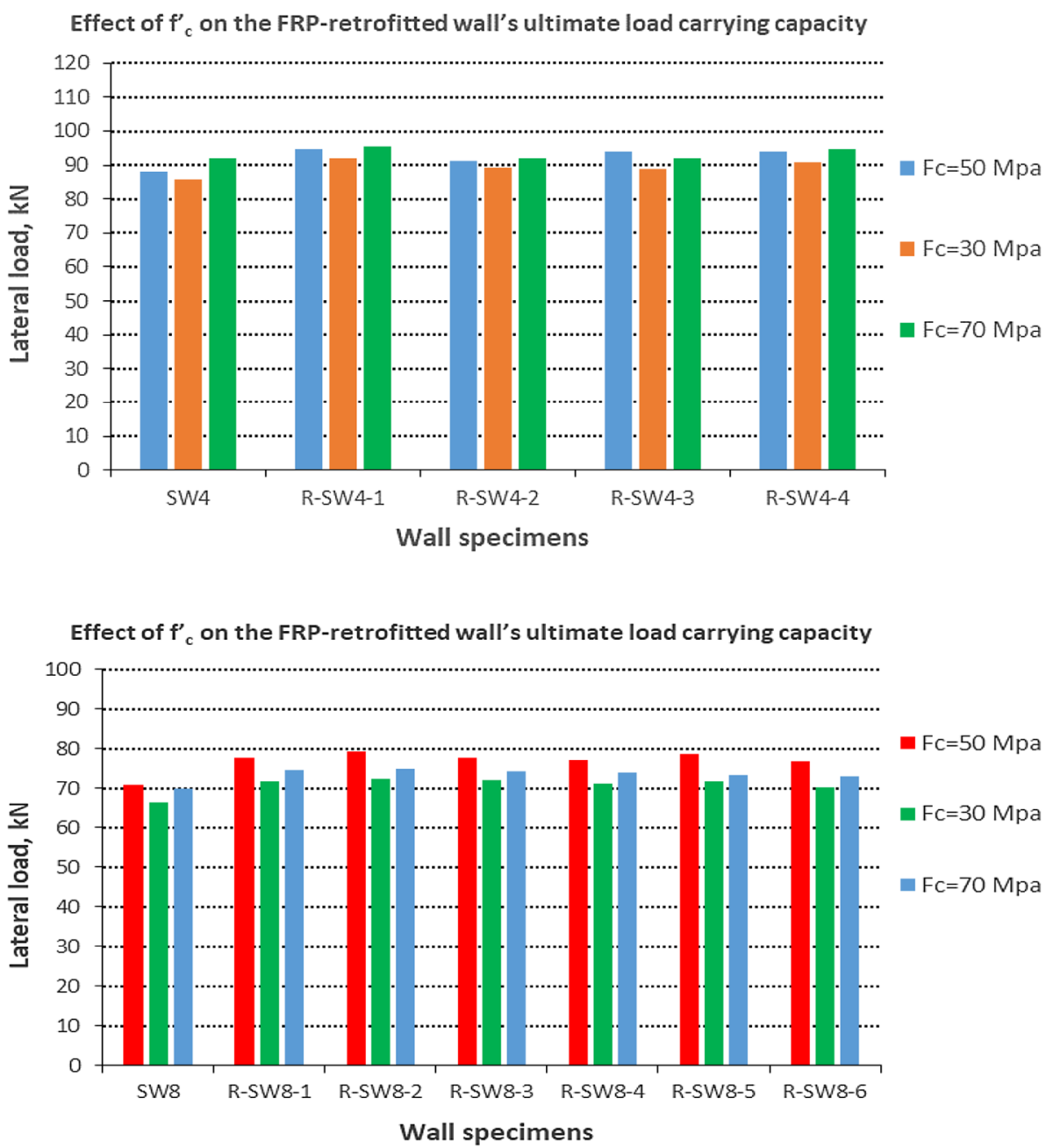

Fig. 21 Effect of $f_{c}^{\prime}$ on the FRPretrofitted wall's ultimate load carrying capacity (R-SW8)
1. Strengthening of RC shear walls with openings using CFRP laminates was an effective technique. The use of CFRP laminates significantly improved the seismic performance of RC walls under hysteretic and monotonic lateral loads.

2. Hysteretic and monotonic lateral responses of strengthened walls resistance, ductility and dissipated energy were considerably increased as the number of CFRP layers is increased. 
Fig. 22 Comparisons of secant stiffness degradation and energy dissipation capacity of all specimens
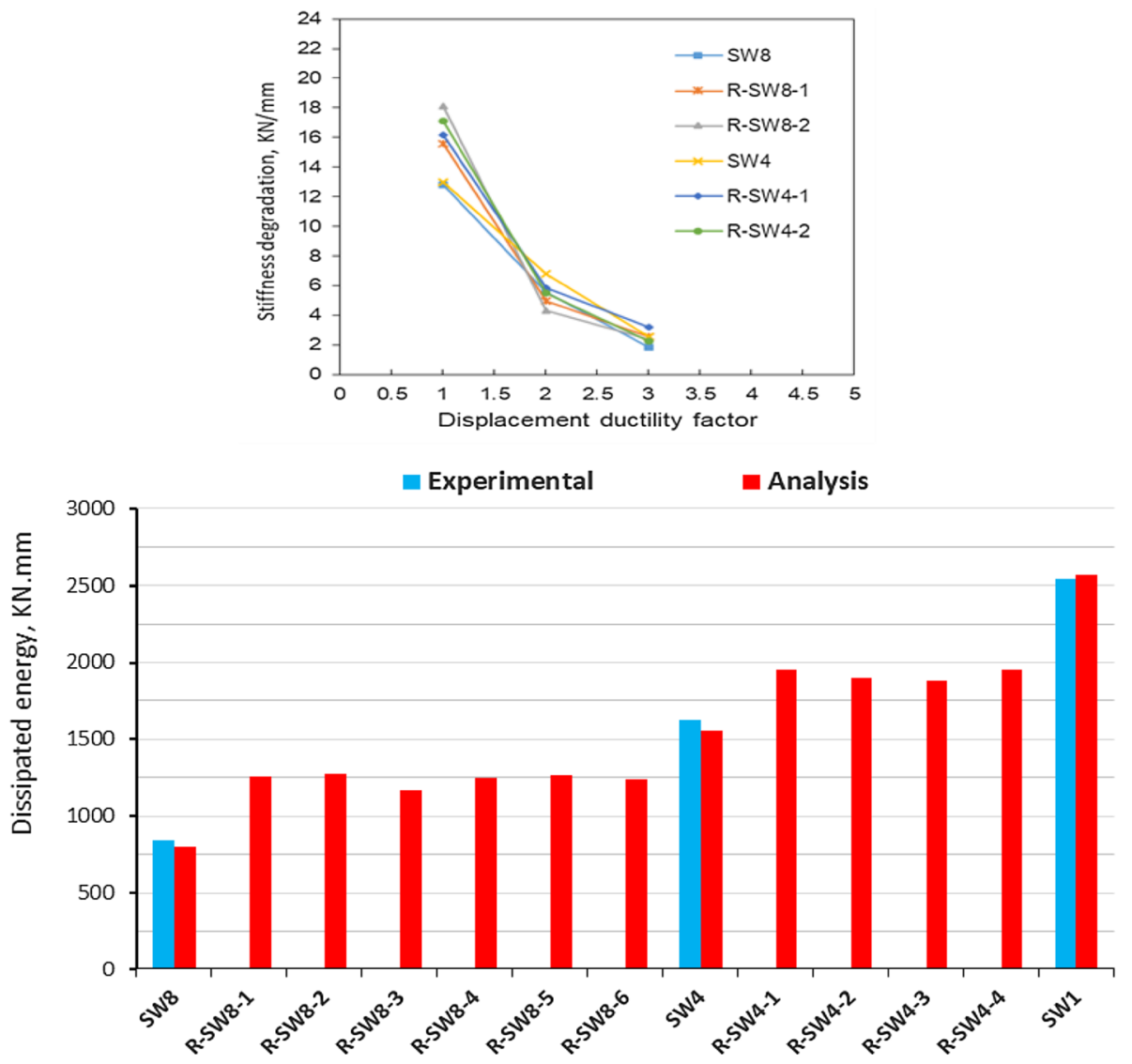

Wall specimens

Table 8 The ductility and energy absorption capacity of wall specimens

\begin{tabular}{|c|c|c|c|c|c|c|c|}
\hline Wall specimen & Peak load, kN & $\begin{array}{l}\text { Peak displace- } \\
\text { ment }\left(\Delta_{\mathrm{u}}\right), \mathrm{mm}\end{array}$ & $\begin{array}{l}\text { Energy absorption } \\
\text { capacity }\left(E_{\mathrm{b}}\right), \mathrm{kN} \mathrm{mm}\end{array}$ & $\begin{array}{l}\text { Yield displace- } \\
\text { ment, }\left(\Delta_{\mathrm{y}}\right), \mathrm{mm}\end{array}$ & $\begin{array}{l}\text { Ultimate dis- } \\
\text { placement }\left(\Delta_{\mathrm{u}}\right) \text {, } \\
\mathrm{mm}\end{array}$ & $\begin{array}{l}\text { Ductility } \\
\text { index, } \mu= \\
\Delta_{\mathrm{u}} / \Delta_{\mathrm{y}}\end{array}$ & Failure mode \\
\hline $\mathrm{CW}$ & 113.63 & 26.32 & 2566 & 10.40 & 26.32 & 2.53 & Flexure \\
\hline SW4 & 88.00 & 21.81 & 1560 & 8.55 & 21.81 & 2.55 & Flexure \\
\hline SW8 & 71.00 & 14.96 & 802 & 8.06 & 14.96 & 1.86 & Shear \\
\hline R-SW8-1 & 77.74 & 15.60 & 1258 & 7.82 & 19.98 & 2.55 & Shear \\
\hline R-SW8-2 & 79.40 & 17.20 & 1275 & 7.77 & 19.92 & 2.56 & Shear \\
\hline R-SW8-3 & 77.80 & 18.14 & 1172 & 8.51 & 19.96 & 2.35 & Shear \\
\hline R-SW8-4 & 77.17 & 17.71 & 1247 & 7.71 & 20.00 & 2.60 & Shear \\
\hline R-SW8-5 & 78.62 & 18.14 & 1263 & 7.75 & 19.96 & 2.58 & Shear \\
\hline R-SW8-6 & 76.77 & 17.71 & 1239 & 7.78 & 19.92 & 2.55 & Shear \\
\hline R-SW4-1 & 94.85 & 16.19 & 1953 & 7.76 & 24.87 & 3.20 & Flexure \\
\hline R-SW4-2 & 91.12 & 23.55 & 1900 & 8.82 & 24.95 & 2.83 & Flexure \\
\hline R-SW4-3 & 93.92 & 17.10 & 1884 & 7.92 & 17.92 & 2.26 & Flexure \\
\hline R-SW4-4 & 93.82 & 23.55 & 1952 & 8.82 & 23.55 & 2.67 & Flexure \\
\hline
\end{tabular}

Where ductility $(\mu)$ is defined as the ratio of value of displacement at failure load $\left(\Delta_{u}\right)$ to the value of displacement at yield load $\left(\Delta_{y}\right)$

3. Walls with staggered openings fail in a different way than those with ordered openings. Walls with regular openings had a brittle failure by crushing the concrete in the coupling beams due to shear forces, followed by yielding of the horizontal reinforcement in these beams. Walls with staggered openings had a ductile failure by 
the yielding of the vertical reinforcement at the base; however, it followed by concrete crushing.

4. Walls with staggered openings failed at levels of seismic forces and at horizontal displacements higher than the forces and the horizontal displacements recorded in the failure mode of walls with regular openings.

5. Good ductility was not observed in specimens R-SW8-3 and R-SW4-3 as expected, although higher load carrying capacity can be obtained and the widening of the diagonal shear crack could be controlled. The most effective way of improving ductility was to use lateral laminates, which were capable of obtaining good ductility and relative high load carrying capacity at the same time.

6. The strengthened specimens dissipated much more energy than the control wall specimen. The ratio of energy dissipation of strengthened specimens to that of the reference specimen was between 1.16 and 1.57.

7. CFRP laminates are not effective on improving the initial lateral stiffness of the retrofitted specimens.

8. Increasing the number of the CFRP laminates increases the ultimate load by about $17 \%$ and $23 \%$ when increasing the number of the CFRP laminates from two to three layers, respectively. The failure of strengthened RC shear wall with openings was dependent primarily on the thickness of FRP as well as the location and size of openings. In models with a large opening, increasing the CFRP laminate thickness leads to increasing their resistance.

Open Access This article is distributed under the terms of the Creative Commons Attribution 4.0 International License (http://creativeco mmons.org/licenses/by/4.0/), which permits unrestricted use, distribution, and reproduction in any medium, provided you give appropriate credit to the original author(s) and the source, provide a link to the Creative Commons license, and indicate if changes were made.

\section{References}

ABAQUS theory manual and users' manual, version 6.10, 2010

ACI 318-16 (2016) Building code requirements for structural concrete and commentary. Building code and commentary. American Concrete Institute (ACI)

Altin S, Anil O, Kopraman Y, Kara ME (2013) Hysteretic behavior of RC shear walls strengthened with CFRP strips. Compos B Eng 44(1):321-329

Antoniades KK, Salonikios TN, Kappos AJ (2003) Cyclic tests on seismically damaged reinforced concrete walls strengthened using fiber-reinforced polymer reinforcement. ACI Struct J 100(4):510-518

Antoniades KK, Salonikios TN, Kappos AJ (2007) Evaluation of hysteretic response and strength of repaired R/C walls strengthened with FRPs. Eng Struct 29(9):2158-2171
Behfarnia K, Sayah AR (2012) FRP strengthening of shear walls with openings. Asian J Civ Eng (Build Hous) 13(5):691-704

Behfarnia K, Shirneshana A (2017) A numerical study on behavior of CFRP strengthened shear wall with opening. Comput Concrete 19(2):179-189

Birtel V, Mark P (2006) Parameterised Finite Element Modelling of RC Beam Shear Failure. In: 2006 ABAQUS users' conference pp 95-108

Demeter I, Nagy-György T, Stoian V, Daescu AC, Dan D (2010) Seismic performance of precast $\mathrm{RC}$ wall panels with cut-out openings retrofitted by externally bonded CFRP composites. In: Proceedings 3rd fib international congress (fib 2010), PCI, paper no. 593

Ghobarah A, Khalil AA (2004) Seismic rehabilitation of reinforced concrete walls using fibre composites. In: Proceedings of the 13th world conference on earthquake engineering, Vancouver, BC, Canada, August, pp 1-6

Hu H-T, Schnobrich W (1989) Constitutive modelling of concrete by using nonassociated plasticity. J Mater Civil Eng ASCA Issue 4:199-216

Kmiecik P, Kamiński M (2011) Modelling of reinforced concrete structures and composite structures with concrete strength degradation taken into consideration. Arch Civ Mech Eng 11(3):623-636

Lombard J, Lau DT, Humar JL, Foo S, Cheung MS (2000) Seismic strengthening and repair of reinforced concrete shear walls. In: Proceeding twelfth world conference on earthquake engineering, silver stream, New Zealand. no. 2032

Lubliner J, Oliver J, Oller S, Onate E (1989) A plastic-damage model for concrete. Int J Solids Struct 25(3):299-326

Mahmoud AM (2012) Strengthening of concrete beams having shear zone openings using orthotropic CFRP modeling. Ain Shams Eng J 3(3):177-190

Mohammed BS, Ean LW, Malek MA (2013) One way RC wall panels with openings strengthened with CFRP. Constr Build Mater 40:575-583

Mosallam AS, Nasr A (2016) Structural performance of RC shear walls with post-construction openings strengthened with FRP composite laminates. Compos Part B Eng. https://doi.org/10.1016/j.compo sitesb (in press)

Mosoarca M (2013) Failure analysis of RC shear walls with staggered openings under seismic loads. Eng Fail Anal 41:48-64

Nayal R, Rasheed HA (2006) Tension stiffening model for concrete beams reinforced with steel and FRP bars. J Mater Civ Eng 18(6):831-841

Nguyen-Minh L, Phan-Vu P, Tran-Thanh D, Truong QPT, Pham TM, Ngo-Huu C, Rovňák M (2018) Flexural-strengthening efficiency of CFRP sheets for unbonded post-tensioned concrete T-beams. Eng Struct 166:1-15

Park R (1989) Evaluation of ductility of structures and structural assemblages from laboratory testing. Bull N Zeal Natl Soc Earthq Eng 22(3):155-166

Popescu C, Sas G, Blanksvärd T, Täljsten B (2015) Concrete walls weakened by openings as compression members: a review. Eng Struct 89:172-190

Saenz LP (1964) "Discussion of equation for stress-strain curve of concrete "by P. Desayi and S. Krishan. ACI J 61(9):1229-1235

Publisher's Note Springer Nature remains neutral with regard to jurisdictional claims in published maps and institutional affiliations. 